UC-721

Issued: May 1995

Discriminators for the Accelerator-Based

Conversion $(A B C)$ Concept Using a

Subcritical, Molten Salt System

E. Arthur

J. Buksa

W. Davidson

D. Poston 


\section{DISCLAIMER}

This report was prepared as an account of work sponsored by an agency of the United States Government. Neither the United States Government nor any agency thereof, nor any of their employees, make any warranty, express or implied, or assumes any legal liability or responsibility for the accuracy, completeness, or usefulness of any information, apparatus, product, or process disclosed, or represents that its use would not infringe privately owned rights. Reference herein to any specific commercial product, process, or service by trade name, trademark, manufacturer, or otherwise does not necessarily constitute or imply its endorsement, recommendation, or favoring by the United States Government or any agency thereof. The views and opinions of authors expressed herein do not necessarily state or reflect those of the United States Government or any agency thereof. 


\section{DISCLAIMER}

Portions of this document may be illegible in electronic image products. Images are produced from the best available original document. 


\title{
DISCRIMINATORS FOR THE ACCELERATOR-BASED CONVERSION (ABC) CONCEPT USING A SUBCRITICAL MOLTEN SALT SYSTEM
}

\author{
E. Arthur, J. Buksa, W. Davidson, and D. Poston
}

\begin{abstract}
Discriminators are described that quantify enhancements added to plutonium destruction and/or nuclear waste transmutation systems through use of an accelerator/fluid fuel combination. This combination produces a robust and flexible nuclear system capable of the destruction of all major long-lived actinides (including plutonium) and fission products. The discriminators discussed in this report are 1) impact of subcritical operation on safety, 2) impact of subcritical and fluid fuel operation on plutonium burnout scenarios, and 3) neutron economy enhancements brought about by subcritical operation. Neutron economy enhancements are quantified through assessment of long-term dose reduction resulting from transmutation of key fission products along with relaxation of processing frequencies afforded by subcritical operation.
\end{abstract}

\section{Executive Summary}

Performance in nuclear systems aimed at destruction of plutonium and other longlived radionuclides is a function of neutron excess that is available and usable under safe operating conditions. The Accelerator-Based Conversion (ABC) and Accelerator Transmutation of Waste (ATW) are two nuclear system concepts aimed at material destruction. In both, the choice of an accelerator/fluid fuel combination enhances available neutron excess by eliminating the requirement to maintain criticality and by providing a fuel form where neutron poison removal is straightforward. This report focuses on discriminators that quantify the value added to a fluid fuel nuclear system through addition of an accelerator-based neutron source. These discriminators are:

- The impact of subcritical operation on safety,

- The impact of subcritical operation and fluid fuel choice on burnout scenarios for plutonium,

- Subcriticality impacts on the destruction of key long-lived radionuclides, and

- The increased flexibility of operation offered by relaxation of the need to maintain criticality in a nuclear system. 
Subcritical Operation - The single most important discriminator between moltensalt critical and subcritical systems is the subcritical system's response to accident initiators leading to reactivity insertions. A fluid fuel system is much less sensitive to changes in fuel composition and fuel characterization needs compared with solid fuels. However, the possibility of a variable behavior in the nuclear fuel feed could produce reactivity insertions. Reactivity insertions can be identified for a fluid fuel plutonium burning system that can be as large as several dollars. The analysis provided in this paper shows that a subcritical system can be robust to such insertions even under the extremely conservative (and unrealistic) assumption that the accelerator remains operational during an off-normal event. This robustness has been confirmed for negative, positive, and null temperature reactivity coefficients under three heat management scenarios-constant heat removal, loss of the heat removal system, and loss of flow.

Reactivity insertions can also be handled via the use of control rods. The analysis shown in this paper indicates a significant change (factor of 10) in control rod worth for a weapons plutonium molten salt system between beginning of life and 900 days operation. Use of the accelerator eliminates dependence of the control rod worth on burnup and fission product build in, allows a subcriticality level to be confirmed and accurately monitored, and eliminates control margin uncertainties.

Material Burnout - For the case of weapons plutonium, the combination of the accelerator-driven, fluid fuel system offers an attractive environment for burnout or burndown of plutonium. Although the analysis was performed for weapons plutonium, the results apply to other applications such as global plutonium management. The use of highly enriched uranium to further burn out weapons plutonium produces the following results:

- Total plutonium destruction of $99 \%$.

- Pu-239 destruction of $99.98 \%$.

- Resulting plutonium discharge isotopics of greater than 20 percent Pu-238 and 60 percent Pu-240 having a heat load of 125 watts/kilogram.

Neutron Economy Enhancements - The use of the accelerator relaxes requirements to maintain criticality in a nuclear system. Relaxation of this need, addition of the accelerator-based neutron source, and use of fluid fuels add to the system's overall neutron excess. This neutron excess can be used to destroy long-lived fission products that are major contributors to dose release possible at a repository site boundary. The key long-lived fission product contributors identified in this analysis are technetium-99 (TC-99), iodine-129 (1-129), and cesium-135 (Cs-135).

Once such fission products have been identified and ranked in importance, the strength of the accelerator-based neutron source (or also equivalently, the level of subcriticality) needed for transmutation can be identified. In the present analysis, Tc-99 was taken as a reference long-lived fission product because of its inventory in spent fuel and its solubility in groundwater. An analysis of a nuclear system which destroyed both actinides and technetium from spent fuel feed and which had reached equilibrium yielded a $k_{\text {eff }}$ approximately equal to 0.95 . Thus, a critical 
system could not be used to simultaneously burn actinides and the long-lived fission product, technetium. After establishment of this $k_{e f f}$, we found that lowering it further by less than 0.05 (to a value around 0.9 , multiplication of 10 ) could lower dose releases by a further factor of four relative to that for technetium. Larger increases in subcriticality produce marginal dose release impacts while increasing the size and cost of the accelerator substantially.

For applications such as global plutonium management and waste transmutation, the fuel in a nuclear system must be cleaned to achieve required material inventory reduction factors that are on the order of 100 to 1000 . Fluid fuel use contributes significantly to the ease of fuel cleanup. However, fuel cleanup frequencies can be stressing under neutron flux conditions typical in a fluid fuel burner system. The use of the accelerator can reduce processing rates by significant amounts (up to a factor of 10 ) for acceptable levels of subcriticality (keff larger than 0.9 )

Fluid Fuel - Although not an accelerator-based discriminator, the use of fluid fuel in the $A B C$ and ATW concepts provides features essential to operation of the system and achievement of application goals. These include the ability to accept a variety of fissile materials as feeds, much-reduced sensitivity to feed components, the enhancement of system excess reactivity through inherent capabilities for neutron poison removal (on-line methods and fuel salt cleanup), and minimization of highlevel waste requiring disposal. 


\section{Introduction}

The Los Alamos Accelerator-Based Conversion concept for plutonium destruction employs an accelerator-driven subcritical blanket that uses a molten fluoride salt fluid fuel. This combination of subcriticality and fluid fuel derives from requirements related to:

- Mission flexibility and ultimate application goals,

- Enhanced operational flexibility, and

- Safety.

This report focuses on "discriminators" that quantify the value added to a fluid fuel nuclear system through addition of an accelerator-based source of neutrons. These discriminators are:

- The impact of subcritical operation on safety,

- The impact of subcritical operation and fluid fuel choice on burnout scenarios for plutonium,

- Subcriticality impacts on the destruction of key long-lived radionuclides, and

- The increased flexibility of operation offered by relaxation of the need to maintain criticality in a nuclear system.

\section{Background}

Performance in nuclear systems aimed at material destruction is a function of neutron excess that is available and usable under safe operating conditions. The choice of the subcritical blanket/fluid fuel combination enhances available neutron excess a) by eliminating the requirement to maintain criticality and b) by providing a fuel form where neutron poison removal is straightforward.

A number of applications for accelerator-based systems share the common feature of elimination of nuclear materials that may pose proliferation and/or environmental threats. The impact of neutron excess on the applications that are discussed below can be summarized as follows:

- Weapons plutonium : allows deep burn.

- Global plutonium and spent fuel waste transmutation: an absolute requirement.

- Long-lived fission product destruction: a key enabler.

\section{A Destruction ("Deep Burn") of Weapons Plutonium}

An ABC system would destroy weapons plutonium at levels greater than $90 \%$ for all plutonium isotopes and greater than $98 \%$ for Pu-239. This high level of destruction aims at elimination of proliferation concerns for weapons plutonium and other issues (such as criticality) that may be associated with the long-term disposal of plutonium. 


\section{B. Destruction of Global Plutonium Inventories}

Worldwide inventories of plutonium contained in spent nuclear fuel are significantly larger than surplus weapons plutonium stockpiles and are growing at a rate of 60 to 80 tonnes per year. This issue was identified as a major concern in the recent National Academy of Sciences study on weapons plutonium disposition 1 .

$A B C$ systems can reduce residual plutonium inventories to levels that are an order of magnitude smaller than reactor-based systems (MOX-fueled light-water reactor with plutonium recycle or fast reactor operating in a conversion mode-rather than plutonium breeding-with fuel reprocessing). (See Figure 1.) The acceleratorbased system can achieve further burnout if the multiplication is allowed to drop in the system and the accelerator is used to provide a larger fraction of the system's neutron source.

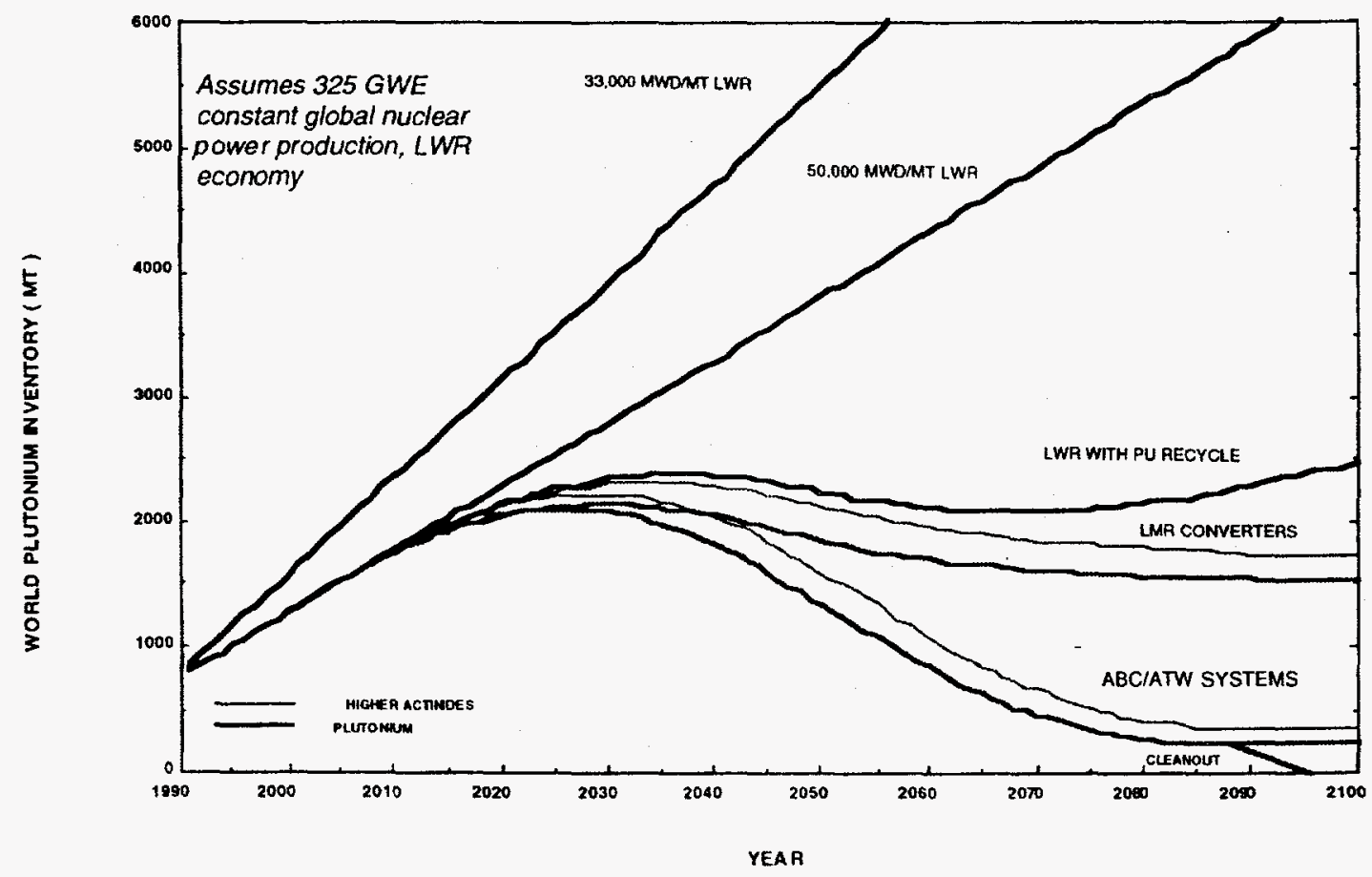

Figure 1: Increase in global plutonium inventories and the impact of nuclear systems (light-water reactor (LWR), liquid-metal reactor (LMR) converter, accelerator-based conversion) for reducing them.

\section{Enhanced Approaches for Disposal of High-Level Nuclear Waste}

Accelerator-based systems can simultaneously destroy plutonium, other long-lived actinides (americium, neptunium, curium) and long-lived fission products (Tc-99, 1-129, Cs-135). By doing so, radionuclides can be eliminated that are main contributors to long-term repository-related dose effects or to effects 
associated with thermal instabilities and criticality issues in repository storage. The operation and requirements for Accelerator Transmutation of Waste (ATW) systems are similar to those described above for $A B C$ systems. A primary difference is that the excess neutron fraction of the system must be high enough not only to burn actinides (plutonium and higher actinides) but also the long-lived fission products as well. The accelerator-based source of neutrons essentially provides the neutrons that transmute long-lived fission products. The degree of subcriticality (determined by the relative strength of the accelerator source versus neutrons from fission in a subcritical blanket) determines the fission product "load" that can be accommodated in an ATW system.

\section{Requirements Overview}

Features (accelerator and/or fluid fuel) that are the major contributor to meeting a given operational requirement for a specific application are outlined in Table 1.

Table 1: Features contributing to meeting operational requirements for accelerator-system applications

\begin{tabular}{|c|c|c|c|}
\hline Application & \multicolumn{3}{|c|}{ Requirement } \\
\hline & Safety/Control & $\begin{array}{c}\text { Neutron } \\
\text { Economy }\end{array}$ & Fuel Cleanup \\
\hline $\begin{array}{c}\text { Weapons Pu } \\
\text { Destruction }\end{array}$ & accelerator & & \\
\hline $\begin{array}{c}\text { Global Pu } \\
\text { Management }\end{array}$ & accelerator & $\begin{array}{l}\text { accelerator } \\
\text { \& fluid fuel }\end{array}$ & fluid fuel \\
\hline $\begin{array}{c}\text { Long-Lived Waste } \\
\text { Destruction }\end{array}$ & accelerator & $\begin{array}{l}\text { accelerator } \\
\text { \& fluid fuel }\end{array}$ & fluid fuel \\
\hline
\end{tabular}

A. Safety and Control

All applications discussed here require levels of safety and control commensurate with those of advanced nuclear power systems. The accelerator provides an important degree of reactivity control in systems where nuclear parameters (delayed neutron fraction, temperature-dependent cross section behavior) are not as favorable as in systems that burn primarily uranium. The degree of subcriticality can be defined at levels where reactivity effects cannot lead to uncontrolled criticality excursions.

B. Neutron Economy

Accelerator systems for destruction of materials that are largely unreactive require enhanced neutron economy. For the application to global plutonium, enhanced neutron economy is needed to permit burning of threshold-fissioner plutonium isotopes (Pu-240 and $\mathrm{Pu}-242$ ) as well higher actinides that build in during operation. For the long-lived waste transmutation system, the accelerator provides the neutron source that transmutes the long-lived fission products that contribute significantly to long-term dose effects associated with repository storage. For both applications, the accelerator-based neutron source and the fluid fuel (which permits rapid removal of neutron poisons) contribute to meeting this requirement. 


\section{Fuel Cleanup}

In systems aimed at global plutonium destruction and long-lived waste transmutation, multiple passes of feed material through the system's neutron environment are required to achieve required burnup. High burnup introduces significant quantities of neutron poisons into the fuel which must be removed. This cleanup must be done with minimal plutonium loss so as to achieve large reduction factors of plutonium inventories (reduction factors of 100 to 1000). The fluid fuel provides attractive features to meet such cleanup requirements.

The subcritical operational environment produced in conjunction with the accelerator provides the robustness required for a liquid fuel system containing variable fissile material feed and inventory isotopics. The remaining portions of this report discuss in more detail discriminators associated with accelerator use. The following sections describe:

- The impact of subcritical operation in providing protection against reactivity insertions that could occur in a fluid-fueled systems (Section IV);

- The impact of the neutron economy (degree of subcriticality) in providing capabilities to significantly reduce long-term dose releases from repository environments (Section VI); and

- The increased flexibility of operation and neutron economy offered by relaxation of the need to maintain criticality in a nuclear system.

(Section VI).

Also discussed is the impact of fluid fuel choice and subcritical operation on "burnout" scenarios associated with weapons plutonium (and applicable to global plutonium inventory reductions) as well as the fluid fuel choice in the context of decreased sensitivity to contaminants and inherent capabilities for neutron poison removal (Sections $V$ and VII). This report is broken out into two broad application categories-the first part that deals with the $A B C$ system for weapons plutonium destruction and the second part that deals with ABC/ATW impacts on broader application areas associated with global plutonium minimization and nuclear waste transmutation.

\section{PART I - IMPACTS OF ACCELERATOR/FLUID FUEL CHOICE ON THE ACCELERATOR-BASED CONVERSION SYSTEM FOR WEAPONS PLUTONIUM DESTRUCTION}

\section{Subcriticality Safety}

The single most important discriminator between molten salt critical and subcritical systems is the subcritical system's response to accident initiators leading to reactivity insertions. A later section (Section VII) will provide an overview of reasons for choosing a liquid fuel for the accelerator-based systems discussed in this report. This approach is characterized by a variable fuel nuclear behavior that is a consequence of variations of the feed material (material source, contaminants present, etc.) and of burnup. This situation is unacceptable for reactors where a complete characterization of the reactivity worth of the fuel is needed to maintain criticality and to guarantee safe operation. 
The following section focuses on the advantages of operating in a subcritical, sourcedriven mode and, in particular, the safety advantages of subcritical operation compared to critical operation for a molten salt system. This discussion is still general because of the preliminary state of the definition of molten salt, Pu-fueled systems. However, even at this early stage, the safety advantages can be discussed quantitatively based on the accelerator system's insensitivity to reactivity temperature feedback coefficient and its response to reactivity insertions.

\section{A Reactivity Insertions in a Fluid Fuel System}

Before discussing the impact of subcriticality on the operation of a fluid fuel system, the magnitude of possible reactivity insertions must be provided. A "bottoms up" analysis was performed that included calculations of specific weapons plutonium fueled systems as well as data from previous analyses ${ }^{2}$ from the Oak Ridge molten salt reactor program. Sources of reactivity insertions and their magnitudes are presented in terms of "dollars" of reactivity inserted. This unit for reactivity insertion, one dollar, is the amount of reactivity needed to induce prompt criticality-i.e.,

$$
\rho \text { (reactivity) }=\beta \text { (delayed neutron fraction). }
$$

Thus, reactivity insertion (in dollars) $=$ reactivity insertion $(\Delta k) / \beta$.

Magnitudes for identified reactivity insertions are summarized in Table II; more background on their determination appears in Appendix $A$.

Table II: Reactivity insertions possible in a fluid fuel plutonium system

\begin{tabular}{|l|l|}
\hline \multicolumn{1}{|c|}{ Mechanism } & \multicolumn{1}{|c|}{ Magnitude (in Dollars) } \\
\hline $\begin{array}{l}\text { Unanticipated fuel } \\
\text { distribution problem }\end{array}$ & up to $\$ 8$ \\
\hline $\begin{array}{l}\text { Fuel feed error (Pu } \\
\text { system-beginning of life) }\end{array}$ & $\$ 1$ for $10 \%$ feed error \\
\hline $\begin{array}{l}\text { Fuel feed characterization } \\
\text { error }\end{array}$ & scenario dependent \\
\hline $\begin{array}{l}\text { Void collapse } \\
\text { Fission product absorber } \\
\text { removal }\end{array}$ & $<\$ 2$ \\
\hline $\begin{array}{l}\text { Temperature change } \\
\text { (heating) }\end{array}$ & $\begin{array}{l}>\$ 1 \text { if temperature } \\
\text { coefficient of } 1 \mathrm{e}-04 \\
(\Delta \mathrm{k}) /{ }^{\circ} \mathrm{C}, \text { minimal for } \\
\text { negative coefficient }\end{array}$ \\
\hline Loss of circulation & $\$ 0.65$ \\
\hline
\end{tabular}

\section{B. Subcritical System Response}

Subcritical systems are inherently resilient to the consequences of reactivity swings. For Pu fuels, this feature is extremely important because of the small delayed neutron fraction relative to $U$ fuels $(\beta P u-239=0.0016, \beta U-235=0.0045)$. In $a$ 
fluid fuel system, the fuel circulates through heat exchangers. The fuel resides for significant amounts of time outside of the neutron flux region so that the effective delayed neutron fraction is reduced. Because $\mathrm{Pu}$ fuels have an already small delayed neutron fraction, this effect reduces the difference between delayed critical and prompt critical and hence reduces the response period following any reactivity insertion. Critical systems employing only $\mathrm{Pu}-239$ as the primary fissile fuel component operate very close to prompt critical and small reactivity insertions of $\$ 1$ or more will lead to uncontrollable excursion periods on the order of $10^{-3}$ seconds (or less for fast spectrum systems). Even critical systems with strong inherent negative reactivity feedback can experience rapid power and temperature peaking during reactivity insertion accidents. Subcritical systems, conversely, equilibrate rapidly at a new power level for any reactivity short of criticality. The time response for the subcritical system can be orders of magnitude longer than for a critical system, and consequently, operator response time is vastly increased. The actual response of the subcritical system depends on the depth of subcriticality.

The comparison between subcritical and critical system response is illustrated graphically in Figure 2. In each of the cases involving subcritical operation, the accelerator source of neutrons is still considered to be operational even though in all present accelerator-based systems, interlocks with key system components prevent accelerator operation under off-normal conditions. This comparison is overly conservative and unlikely. The rapid shutoff time (10s of milliseconds) for the accelerator is orders of magnitude smaller than the very conservative response times shown in Figure 2.

Results from reactor kinetics calculations have been made for critical $\left(k_{\text {eff }}=1\right)$ and subcritical ( $k_{\text {eff }}=0.94,0.96,0.98$ ) systems containing plutonium under conditions where the slope of the temperature feedback coefficient of the system is flat (null value). The assessment is made for the response time inherent in the system before the bulk fuel temperature reaches an arbitrary upper-limit temperature of $1500 \mathrm{~K}$. Three scenarios are considered-constant heat removal (heat is removed at the steady state rate), loss of the heat removal system (fuel continues to flow, but no heat is removed), and loss of flow (the fuel is stagnant due to total blockage or total loss of primary pump operation). In Figure 2, the shaded bar indicates the range of reactivity insertions provided in Table II. Portions of the shaded bar lying to the right of the curve associated with the respective critical system or subcritical system response mean that the system essentially has no time to respond to the effects resulting from the reactivity insertion.

For the range of reactivity insertions illustrated in Table $\mathrm{II}$, the critical fluid fuel system has essentially no response time to react before temperature excursions become unacceptable. Especially interesting is the loss-of-flow scenario where an automatic reactivity insertion occurs in fluid fueled systems because of an effective increase in the delayed neutron fraction resulting from the lack of fuel circulation. This small insertion $(<\$ 1)$ has a detrimental effect upon the critical system, while it minimally affects the subcritical systems. In all cases, the subcritical system, even under the rather unrealistic assumption that the accelerator beam stays on, provides significant margin for response and shutdown. This margin obviously increases as the subcriticality of the assembly increases.

Appendix $B$ describes the kinetics model used to evaluate reactivity insertion impacts while Appendix $\mathrm{C}$ gives more detail concerning system response for situations of positive and negative reactivity temperature feedback. These analyses illustrate the robust safety of subcritical systems, even with positive prompt reactivity feedback. 
Constant Heat Removal

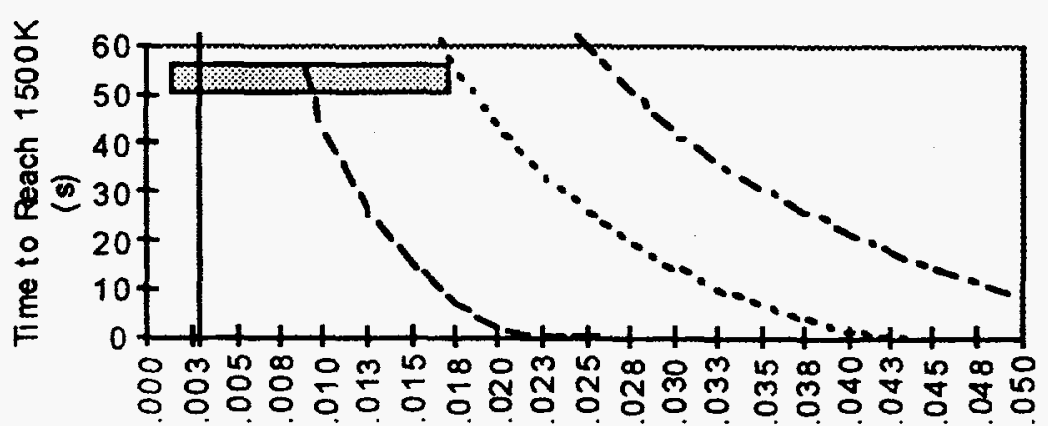

Reactivity Insertion $(.00212=\$ 1)$

Loss of Heat Removal System

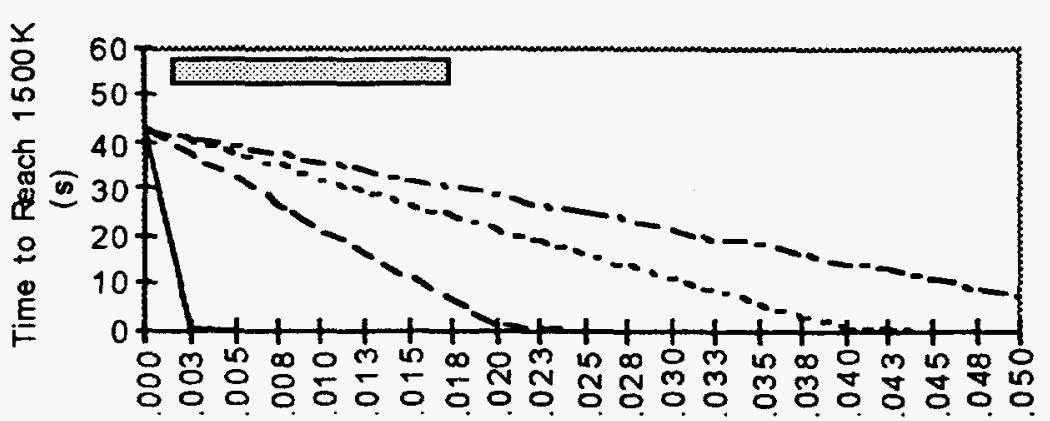

Reactivity Insertion $(.00212=\$ 1)$

\section{Loss of Pumps (No Flow)}
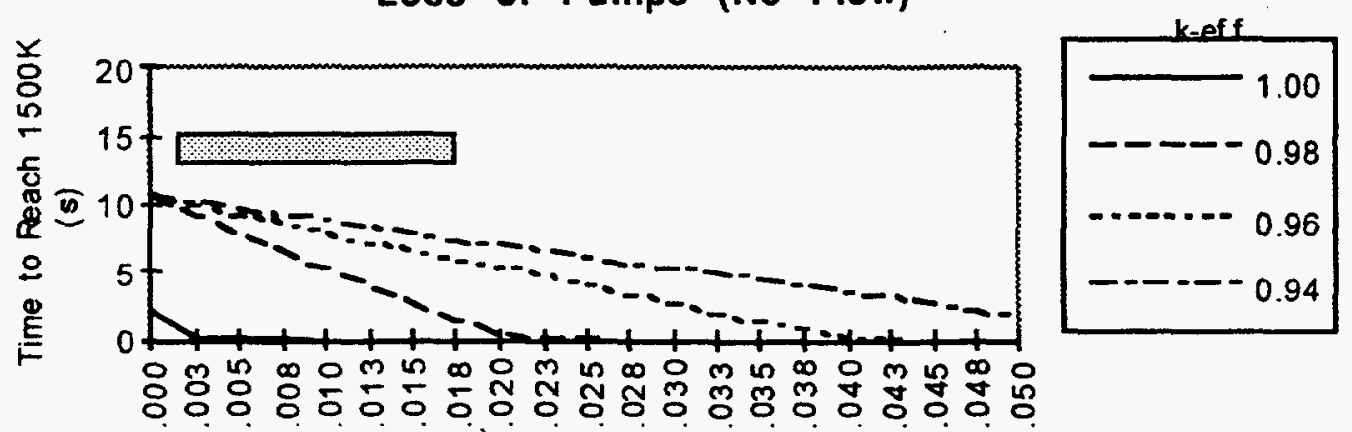

Reactivity Insertion $(.00212=\$ 1)$

Figure 2: Accident response of $500 \mathrm{MW}(\mathrm{t})$ molten-salt weapons plutonium system with flat isothermal reactivity temperature coefficient. The shaded bar indicates ranges of possible reactivity insertions identified in Table II.

For subcritical systems, the sign of the prompt reactivity feedback only marginally affects the temporal response of the system. Critical systems, on the other hand, must have prompt negative reactivity feedback features to meet modern safety requirements. Without this feature, critical systems are unstable and uncontrollable. 
The discussion above presented accident response results for an assumed null value for the temperature dependence of the system's reactivity coefficient. Appendix $C$ provides additional information for negative and positive values for the reactivity temperature coefficient. The actual reactivity temperature coefficient for an $A B C$ system is a function of design choices and fuel material composition. It also depends upon changes in nuclide isotopics that occur as the system operates. As a reminder, the weapons-burning $A B C$ system is postulated to operate on a multiyear (up to ten year) burn cycle. At the beginning of life, the system contains a relatively small inventory of essentially pure (93 per cent) Pu-239. As the system operates, other plutonium isotopes build in that affect the reactivity temperature coefficient of the system. The preliminary temperature coefficient that has resulted based on the beginning design definition of the $A B C$ molten salt blanket is shown in Figure 3 . This preliminary temperature coefficient is appropriate for beginning-of-life operational conditions.

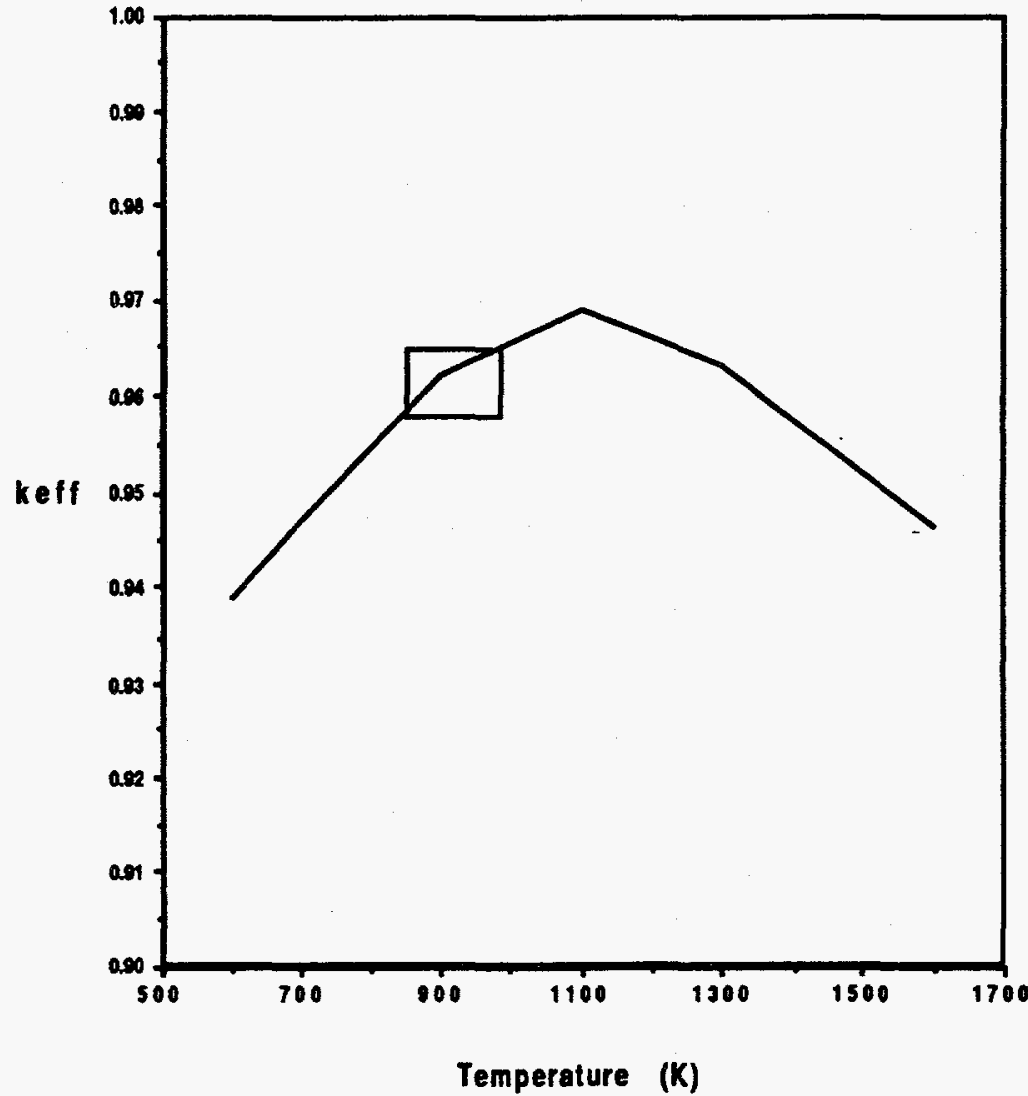

Figure 3: A value for the reactivity temperature coefficient that has resulted from preliminary analyses under beginning-of-life condition assumptions. The box indicates normal temperature ranges for the system. 
In this preliminary analysis, the temperature coefficient shows a positive behavior over the normal operating range for the system, while at elevated temperatures associated with a number of accident scenarios, the dependence becomes negative. At lower temperatures closer to the salt melting point, the system $k_{\text {eff }}$ drops, thus preventing conditions of criticality during conditions of system shutdown. The results shown here are provided as an example only and are for beginning-of-life conditions. The actual value determined for the reactivity temperature requires more design iterations and may involve use of burnable poisons during the relatively short beginning-of-life period. The temperature coefficient shape will be altered significantly as system operation progresses and additional plutonium isotopes such as Pu-240 become major constituents of the fuel mix isotopics.

\section{Subcritical Operation Versus Use of Control Rods}

The use of an accelerator is sometimes unfairly characterized as an expensive control rod. More accurately, there are three principal arguments why subcritical operation enabled by use of the accelerator is preferable to the use of control rods in a critical fluid fuel system:

1. The level of subcriticality can be chosen to provide an absolute margin for protection against unforeseen reactivity insertions. This subcriticality level can be monitored accurately.

2. The response of an accelerator-driven system to off-normal conditions is fast (less than 10 milliseconds is a typical response) and complete-once the accelerator is turned off, the driving neutron source for the multiplying assembly stops. Control rod insertion is slower (on the order of seconds) and can be unintentionally interrupted because of mechanical, alignment, or other unanticipated difficulties.

3. In a system which is used for material destruction under conditions where the system's reactivity and isotopics mix changes as a function of time, control rod worth can change significantly. It may be possible, under certain circumstances, that control rod worth may not be known precisely enough to ensure adequate control.

The latter issue was examined quantitatively for a molten salt blanket of the type considered for $A B C$ concepts. Control rods that displaced fuel salt were added to the model for the ABC blanket. Fuel displacement was chosen because this was the control approach chosen in earlier Oak Ridge molten salt reactor concepts. The results are summarized in Table III.

Table III: Control rod worth effects versus type and system operational time

\begin{tabular}{|c|c|l|c|}
\hline $\begin{array}{c}\text { System } \\
\text { Operational } \\
\text { Time }\end{array}$ & $\begin{array}{c}\text { Salt } \\
\text { Displacement } \\
(\text { Blanket Vol \%) }\end{array}$ & \multicolumn{1}{|c|}{ Material } & Worth $(\$)$ \\
\hline $\mathrm{BOL}^{*}$ & 1.0 & void & 1.3 \\
\hline $\mathrm{BOL}$ & 1.0 & stainless steel & 10.2 \\
\hline 900 days & 1.0 & void & 1.2 \\
\hline 900 days & 1.0 & stainless steel & 1.5 \\
\hline
\end{tabular}


Two conclusions come from this study:

1. Control rod worths can change by an order of magnitude in a plutonium burning system over less than a three-year operational time.

2. For this form of control to be effective, a significant volume of fuel salt would have to be displaced to produce a required control worth.

\section{Further Burnout of Plutonium in an Accelerator-Driven Molten Salt System}

The combination of the $A B C$ subcritical molten salt system provides attractive conditions for further destruction of plutonium through use of a highly enriched uranium (HEU) burndown mode. Because of subcriticality, the system is extremely robust with respect to a significant change in the fissile fuel introduced into the molten salt carrier. Subcritical operation permits the introduction of HEU with minimal needs for fuel certification. In addition, the uranium preferentially takes the +4 oxidation state which is highly soluble in the molten salt so that significant amounts can exist in the salt without concern for materials precipitation.

For this analysis, the plutonium burn strategy was assumed to be a two-phase operation in which the first phase is a weapons plutonium fueled power production cycle whose length $(\sim 10$ years) is determined by salt solubility limits for the actinides and the fission-product lanthanides. The second phase is a HEU-fueled (with residual $\mathrm{Pu}$ ) power production cycle whose length ( $3-5$ years) is determined by maximum Pu burndown requirements. For calculational simplicity, the initial fuel feed in Phase 2 is assumed to be only residual Pu until its inventory is depleted ( 3 months). The calculated plutonium burnup performance in Phase 2 is presented in Figure 4. Within one year's operation time, the Pu-239 burnup approaches its maximum of $99.98 \%$. The inventory of residual plutonium at the end of burndown is extremely unfavorable for weapons applications as shown in the plutonium mass fraction isotopics illustrated in Figure 5 . The high-thermal power Pu-238 is greater than twenty percent of the total, while the low fission Pu-242 is sixty percent of the total. The resulting heat load of the residual plutonium mixture is approximately 125 watts/kilogram, a value that would lead to heat loads higher than those assumed practical ${ }^{3}$ for a nuclear explosives utilization.

This burndown scenario again results from the flexibility of the accelerator subcritical operation/fluid fuel combination. Operation in the subcritical mode allows widely varying fuel types and isotopics to be used in the blanket without need for extensive characterization and in a mode that is robust against possible reactivity excursions. Use of the fluid fuel form allows uranium to be added to the fuel feed without need for extensive fuel characterization or system recertification. The major operational change would be a change in the system's oxidation potential (redox control) which is a straight forward process. Appendix D provides additional details concerning this burnout scenario analysis. 


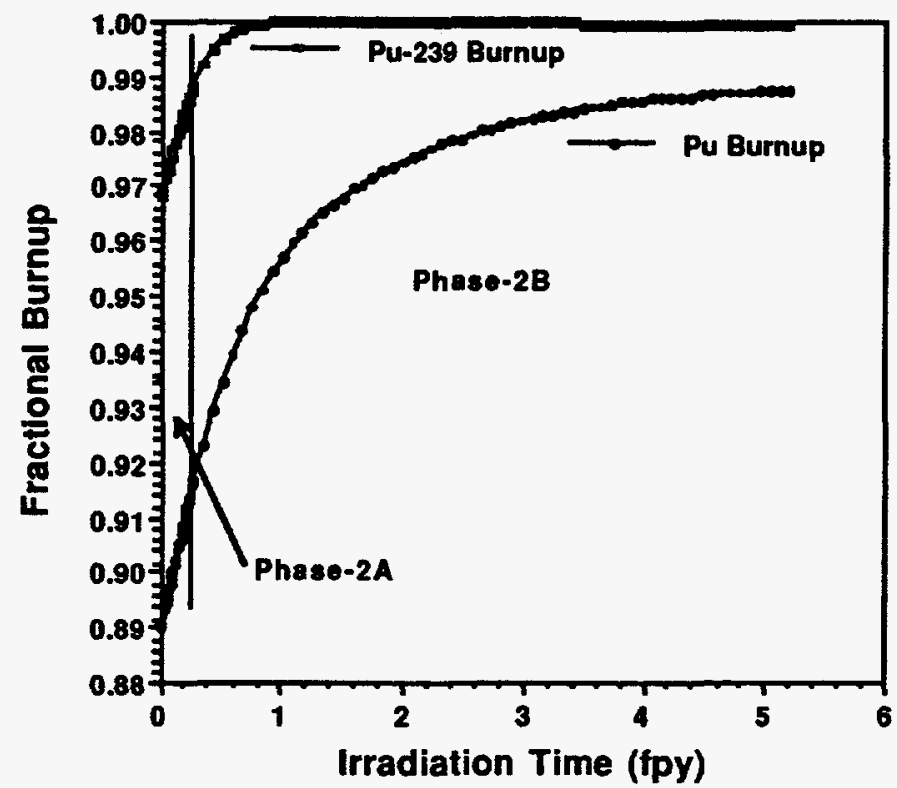

Figure 4: Plutonium and Pu-239 fractional burnup calculated during Phase 2 burndown. Phase $2 A$ includes plutonium, while Phase $2 B$ has HEU feed.

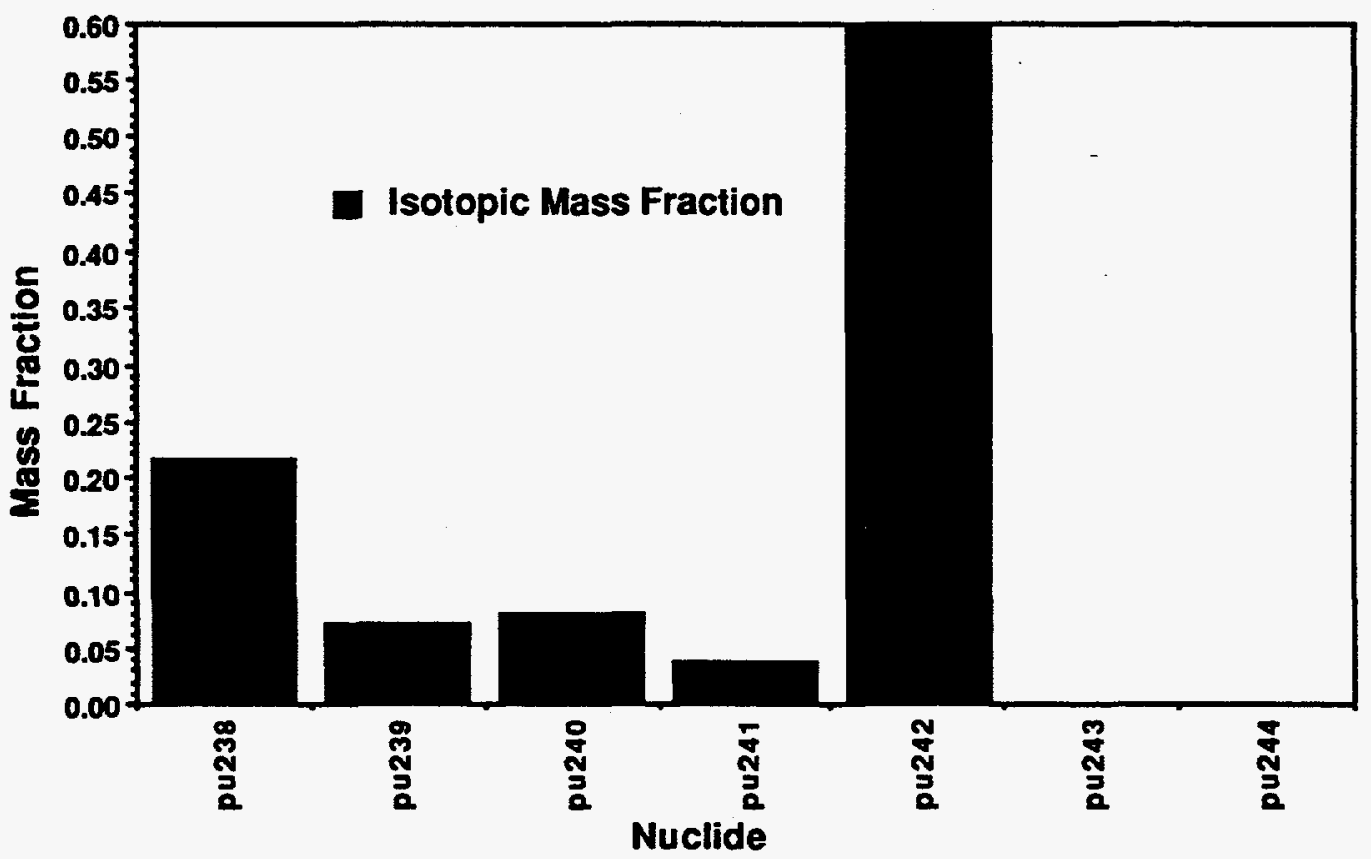

Figure 5: Plutonium isotopics after a HEU burnout phase. 


\section{PART II - IMPACTS OF ACCELERATOR FLUID FUEL SYSTEM CHOICE ON GLOBAL PLUTONIUM MINIMIZATION AND WASTE MANAGEMENT APPLICATIONS}

\section{Neutron Economy Impacts on Long-Lived Waste Destruction}

Neutron utilization in subcritical fissioning systems can be significantly better than in a critical system because fewer of the neutrons in the system must be used to sustain neutron-producing fission reactions. This neutron excess can be used to destroy non-fissile, long-lived radionuclides or to mitigate performance impacts resulting from parasitic losses.

This section describes the utilization of this neutron excess to transmute long-lived fission products and/or to relax fuel processing requirements. The following areas are presented:

- Long-lived fission products that are key contributors to possible dose release arising from repository storage are identified.

- The overall impact of keff on the availability for excess neutrons is discussed.

- The maximum keff appropriate for destruction of the key fission product Tc-99 is determined.

- The increment improvement in repository dose reduction versus keff in the system is provided.

- The impact of subcriticality on fuel cleanup rates needed in a fluid fuel system is presented.

Transmutation of the long-lived fission products (LLFPs) present in spent reactor fuel or those produced in plutonium and other actinide burning requires a significant neutron excess. Such an excess is difficult to obtain in a critical system. An accelerator-driven subcritical system allows a variable neutron excess that depends upon the degree of subcriticality. The seven LLFPs and their yearly production in reactor spent fuel are presented in Table IV.

\section{A. Key Fission Product Contributors to Dose Release from Geologic Storage}

In a recent assessment of the impact of actinide and fission product transmutation on waste repository performance, Pigford 4 found that some LLFPs were much more significant dose contributors to the biosphere in releases from a repository than the major actinides. These results were largely based on the high solubilities of the these LLFPs with respect to the actinides. Pigford defined the "relative dose index" (RDI) parameter as a measure of the dose rate of a released radionuclide species relative to that of the dominant LLFP species TC-99. (The dose rate was taken at the boundary to the biosphere and at the time of initial release.) This parameter accounts for both decay and sorption on rock as the species migrate from the repository and thus is a function of the water travel time to the biosphere boundary. 
The RDI values presented by Pigford are shown in Figure 6 . Note that except for long water travel times, the LLFPs 1.129 and Cs-135 are larger release-dose contributors than any of the major actinides. Pigford did not include the other LLFPs because of their lower solubilities.

Table IV: Masses of long-lived fission products in spent pressurized water reactor (PWR) fuel (10-yr-old, 33GWd/ton burnup)

\begin{tabular}{|c|c|c|c|}
\hline LLFP & $\begin{array}{c}\text { Half Life } \\
(y)\end{array}$ & $\begin{array}{c}\text { Mass in } \\
\text { Spent Fuel } \\
(\mathrm{g} / \mathrm{MTHM})\end{array}$ & $\begin{array}{c}\text { Isotopic } \\
\text { Fraction } \\
\text { of Element }\end{array}$ \\
\hline $\mathrm{Se}-79$ & $6.50 E+04$ & 5.87 & 0.10 \\
\hline $\mathrm{Zr}-93$ & $1.50 E+06$ & 718.60 & 0.20 \\
\hline $\mathrm{Tc}-99$ & $2.13 E+05$ & 770.90 & 1.00 \\
\hline $\mathrm{Pd}-107$ & $6.50 E+06$ & 218.20 & 0.16 \\
\hline $\mathrm{Sn}-126$ & $1.00 E+05$ & 27.39 & 0.16 \\
\hline $\mathrm{I}-129$ & $1.57 E+07$ & 178.80 & 0.76 \\
\hline $\mathrm{Cs}-135$ & $2.30 E+06$ & 300.00 & 0.13 \\
\hline
\end{tabular}

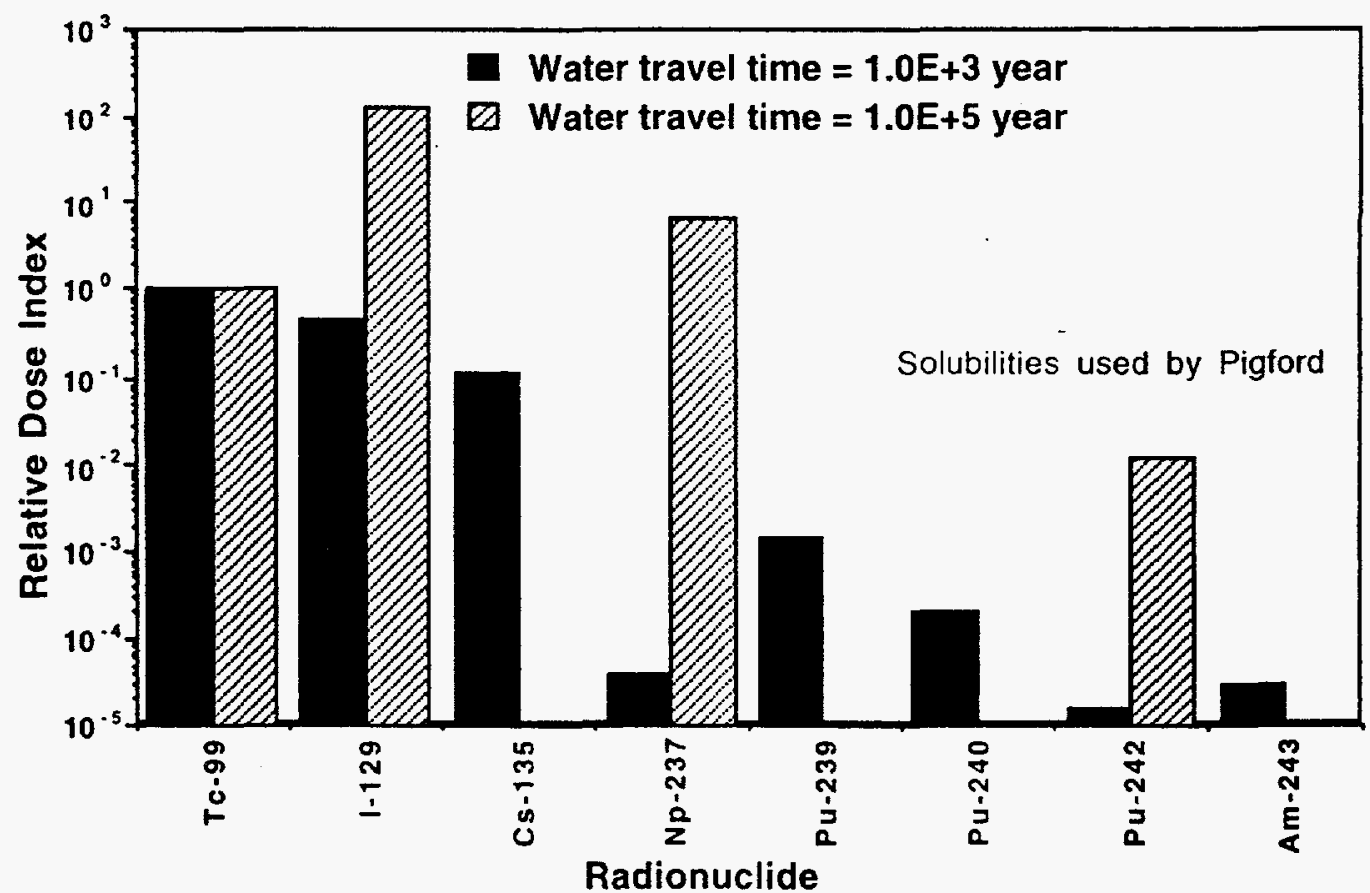

Figure 6: The Relative Dose Index calculated by Pigford ${ }^{4}$ for repository release of dominant actinides and LLFPs for water travel times of 1000 and 100,000 years. 
The actinide solubilities used by Pigford were those of actinide metals; however, recent Yucca Mountain performance assessments 5 recognize that the oxide solubilities are the relevant values. These values are from $10^{3}$ to $10^{5}$ larger than those use by Pigford. If Pigford's methodology is modified for these more recent actinide solubilities, the actinides become larger contributors to the repository release dose, but the some of the LLFPs still remain as equally significant contributors. Thus, if transmutation is to effect significant reductions in the repository release dose, the transmutation strategy must include the LLFPs in addition to the actinides.

In order to provide an expanded methodology for determination of possible dose releases to the environment, an analytical model was developed. Its derivation is provided in Appendix $E$, and results will be used here to identify which fission products represent major contributors to dose released to the accessible environment. From this model, the total integrated dose per unit volume of contaminated water in the accessible environment at reference post-release time tR due to radionuclide i $D_{i}(t R)$ (rems) is given by:

$$
D_{i}\left(t_{R}\right)=\frac{c_{i}}{\lambda_{i}} \beta_{i}\left(t_{E}\right) \gamma_{\gamma}\left(t_{W}\right) \delta_{i}\left(t_{R}\right) I_{i}^{0}
$$

where

$i^{\circ} \quad$ is the total initial inventory of radionuclide $i$ in the repository,

$c_{i} \quad$ is a dose conversion factor (rem per $\mathrm{dis} / \mathrm{m}^{3}$ );

$\lambda_{i} \quad$ is the decay constant for radionuclide $i$;

$B_{i}(t E)$ is a function of $t E$ (the time at which complete and instantaneous failure of the engineered barrier-e.g., waste canister-in a geologic repository occurs) and $f_{i}$ (the fractional dissolution rate-from waste solid form-of radionuclide $i$ in ground water);

$\gamma_{1}(t w)$ is a function of $t w$ (the ground water travel time to the accessible environment) and $K_{i}$ (the retardation factor-sorption on the geologic media-for radionuclide i); and

$\delta_{i}\left(t_{R}\right)$ is a function of th (the time after radionuclide begins to enter the biosphere).

Model parameter values for LLFPs are given in Appendix E.

To identify key fission product contributors, a relative dose (the ratio of total integrated dose to that for a reference LLFP species-e.g., Tc-99) is defined. This ratio is a measure of the relative benefit of management of other LLFPs compared to TC-99. The use of Tc-99 as a reference follows that from the Pigford methodology and is based on both the large solubility of technetium and the amount of this radionuclide species relative to the other LLFP species.

The value of the normalized (to Tc-99) integrated dose described above is presented in Figure 7 as a function of water travel time for a post-release time of one million years. The radionuclide-dependent data used (presented in Appendix E) is that of Pigford with unknown retardation data equal to that for Cs-135 and the unknown dissolution data equal to that for Tc-99. 


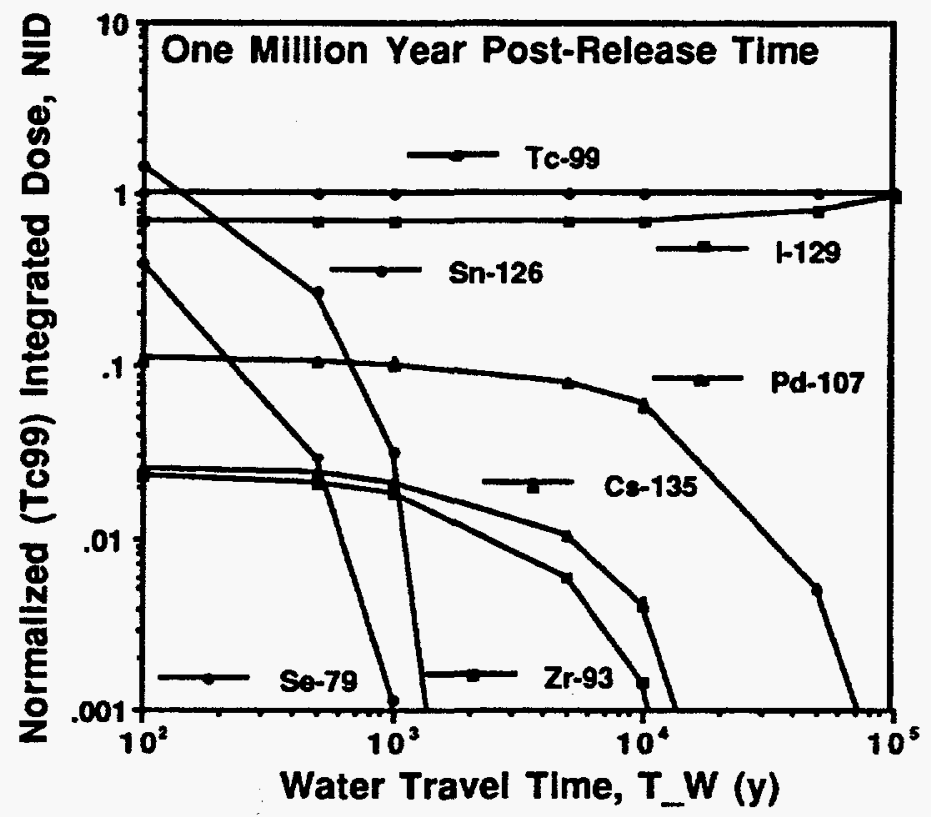

Figure 7: Calculation of the integrated dosed ratio at a post-release time(tR) of $1.0 \times 10^{6}$ years as a function of water travel time and an engineered barrier lifetime ( $t E$ ) of 1000 years.

\section{B. Impact of LLEP Transmutation on Fluid Fuel System Neutron Economy}

The impact of LLFP transmutation on the neutron economy of a fluid fuel nuclear system can be assessed in terms of the dose reduction results presented above. To do this, the source multiplication parameter is used. The keff is fundamentally a neutron economy parameter which measures the fraction of excess neutrons produced in fission which are required to sustain the fission rate. This excess neutron fraction is used to transmute the long-lived fission products discussed in Section $A$ above. The value of keff is a function of several other neutron economy parameters which are described in Appendix $F$. These include the average number of neutrons liberated per fission, $v$, the system neutron non-leakage probability, and a number of values for neutron captures in the system per fission in the fuelcapture in the fuel, capture in structure, captures in parasitic fission products, and capture in any LLFP that may be in the system for transmutation.

The LLFP dose reduction methodology described above and in Appendix $E$ has been extended and coupled to the neutron efficiency of LLFP transmutation in order to compare LLFP transmutation/management strategies. Such a strategy is defined as the number and isotopics of LLFPs to be transmuted as well as whether externally and/or internally generated LLFPs are to be transmuted. This extended methodology 
is described in Appendix $G$. The parameter $W_{i}$ is defined as the integrated LLFP dose reduction (due to transmutation of LLFP species $i$ ) per neutron capture per total LLFP transmutation and is given by

$$
W_{i}=\frac{d_{i}\left(t_{R}\right)}{g_{L L}^{i}\left(1+g_{T P}^{i}\right) y_{L L}^{i}}
$$

The parameter

$d_{i}\left(t_{R}\right)$ is the integrated dose reduction per nuclide or $D_{i}\left(t_{R}\right) / l_{i}^{0}$ as defined above.

The other parameters are transmutation and absorption efficiency parameters for LLFP chains:

$g_{L L}$ is the number of total captures in LLFP species $i$ chain per LLFP nuclide fed to the chain at equilibrium,

gi $_{\text {TP }}$ is the number of total captures in related TP chains per capture in the LLFP species i chain, and

$y^{\prime} L L \quad$ is the species i fraction (isotopic or elemental) of the total number of LLFPs (isotopic or elemental) to be transmuted.

In order to assess the relative dose reduction effectiveness per neutron utilized, the ratio of $W_{i}$ to that for a reference LLFP species (e.g., Tc-99) is calculated. The value of this ratio for a reference transmutation strategy (Appendix G.1) and the same radionuclide dependent data used above (see Figure 7) is presented in Figure 8 as a function of three water travel times. From this figure, it can be seen that significant reductions in possible dose releases can be obtained from the transmutation of technetium, iodine, selenium, tin-126 (Sn-126), and Cs-135. The noble metals, zirconium and palladium, are not major contributors to the environmentally accessible dose even though their relative amounts to be transmuted are large.

Using values for captures in LLFP to be transmuted, a value of the cumulative dose reduction (relative to $T c-99$ ) as a function of $\Delta k_{e f f}$ can be calculated (see Appendix $\mathrm{H}$ ). Before doing so, the reference value of keff for burning Tc-99 and actinides present in spent fuel must be determined. This requires knowledge of the representative values of other neutron economy parameters briefly described above. These parameters are provided in Table $V$ and are based on equilibrium burning of spent-fuel actinides in a well-moderated target-blanket neutron flux spectrum. The assumption of equilibrium conditions is appropriate for a transmutation system that involves multiple recycle of nuclear waste products and feed. 


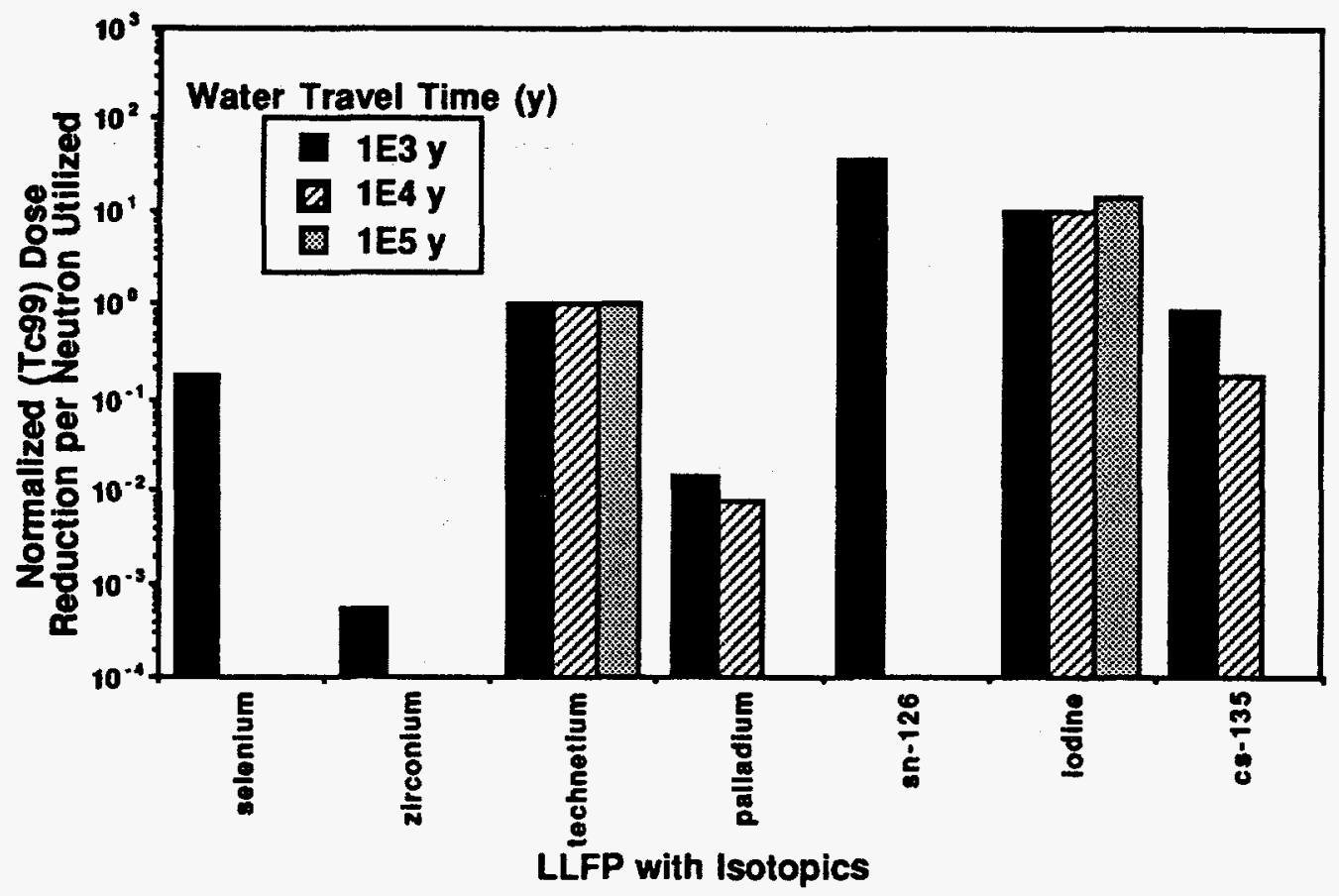

Figure 8: Values of the dose reduction per neutron utilized (relative to the technetium standard) are presented for the long-lived fission products discussed here. The engineered barrier lifetime is 1000 years and the post-release time is $1.0 \times 10^{6}$ years.

Table V: Reference neutron economy parameters and resultant keff for Tc-99 transmutation

\begin{tabular}{|l|c|}
\hline \multicolumn{1}{|c|}{$\begin{array}{c}\text { Neutron Economy } \\
\text { Parameter }\end{array}$} & Equilibrium Value \\
\hline$v$ & 3.045 \\
Nonleakage & 0.984 \\
Structure capture & 0.175 \\
Fuel capture & 1.603 \\
Parasitic FP capture & 0.15 \\
Capture in technetium & 0.24 \\
\hline Resultant Keff & $\mathbf{0 . 9 4 5}$ \\
\hline
\end{tabular}

Using these assumptions for nuclear parameters in a transmutation system, it is not possible to reach criticality in this system when transmutation of fission products is an objective. With this keff in hand, the effect of further reductions in keff on the dose release (relative to technetium) can be made. The results are shown in Figure 9. Note that most of the dose reduction is achieved when only a few LLFPs are transmuted and the resulting $\Delta k_{e}$ eff (beyond that required for Tc-99 transmutation) is small. Since operation at large $\Delta k_{\text {eff }}\left(k_{\text {eff }}<0.9\right)$ translates into large accelerator requirements and hence cost, there is minimal incentive for destruction of 


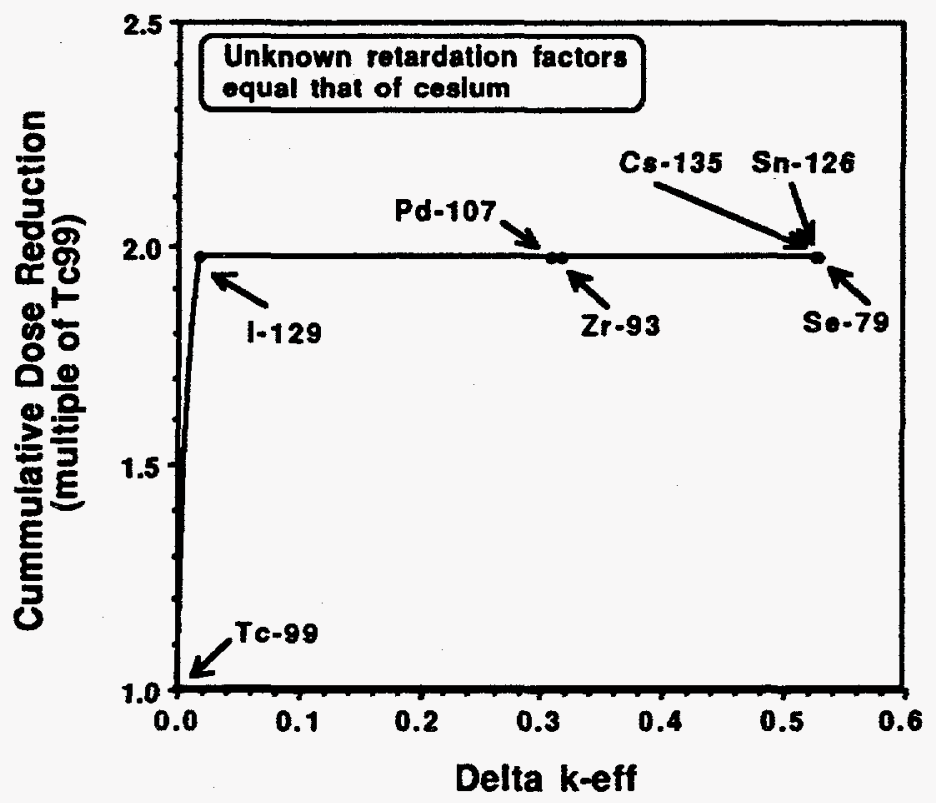

Figure 9: Cumulative LLFP dose reduction as a function of $\Delta k$ eff.

radionuclides which contribute relatively little to dose reduction but which can lead to significant lowering of the system's keff. Appendix $\mathrm{H}$ provides more information concerning fission product absorption effects on the neutron economy of a nuclear system.

C. Contribution of Parasitic Fission Product Absorption to Reactivity

The parameter representing the parasitic losses from neutron absorption on fission products that build in from fuel fission (the lumped fission product alpha, $\alpha F P$ ) is determined by the fission product cross sections and the relative rates of fission product species production from fission and recovery in fuel cleanup. It is a function of the average neutron flux seen by the fission product containing fuel, an averaged "lump" fission product absorption cross section, and a characteristic cleanup time for the fission products.

The value of $\alpha$ FP varies as the fission product isotopics (and hence lump absorption cross sections) shift with time. An equilibrium value is reached in times which are short with respect to blanket module lifetimes. The variation of $\alpha F P$ with flux level and characteristic fuel cleanup time is presented in Figure 10.

Note that for the high fluxes associated with economic, compact, and low-inventory systems, processing requirements can become stressing. The ability to relax the cleanup requirements with an accelerator-driven subcritical system allows another degree of freedom in the performance design optimization. Fuel cleanup adds the excess reactivity needed for both "deep burn" and for additional burn requirements (e.g., higher actinides and/or LLFPs). Robustness with respect to the selection and performance of the various cleanup processes can be an essential element in achieving these burn goals. 


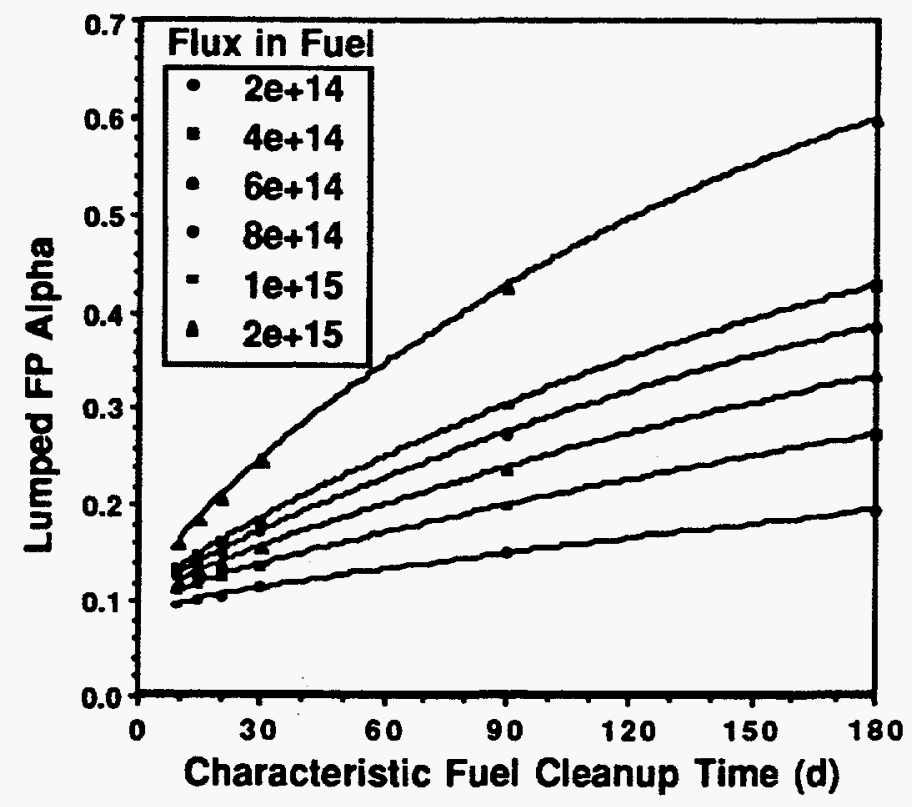

Figure 10: The parameter $\alpha$ FP calculated at equilibrium with ORIGEN2 for a predominantly plutonium fuel and a well-moderated thermal spectrum.

The incremental impact of the behavior of the parasitic losses on fission products that build in during operation on neutron multiplication is presented in Figure 11. The reference keff is taken as that for an ABC/ATW spent-fuel actinide burning system with low average flux in the fluid fuel loop $\left(2 \times 10^{14} \mathrm{n} / \mathrm{cm}^{2}\right.$-s) and a rapid characteristic fuel cleanup time (10 d). Note that fuel cleanup rates can be relaxed by almost an order of magnitude while still maintaining attractive economic operation (keff $>0.9$ ).

\section{Fluid Fuels}

The discussion thus far has focused on discriminators brought to the $A B C$ system through use of an accelerator. This section discusses the justification for the fluid fuel choice.

The $A B C$ system fuel composition management (FCM) strategy has the following main features:

1. The system is geared to accept a number of fissile materials (plutonium, americium, neptunium) in a variety of forms (rich metals and/or oxides from pits, rich scrap, unirradiated fuel, lean scrap, spent fuel). 
2. Maximum burnup is achieved because reactivity losses due to neutron poison buildup are compensated for by continuously adding fissile fuel into the system and key noble metal fission products (poisons) are removed via inherent mechanisms associated with the molten salt fuel.

3. The generation of high-level waste is minimized via a salt cleanup step at the end of the plutonium destruction campaign.

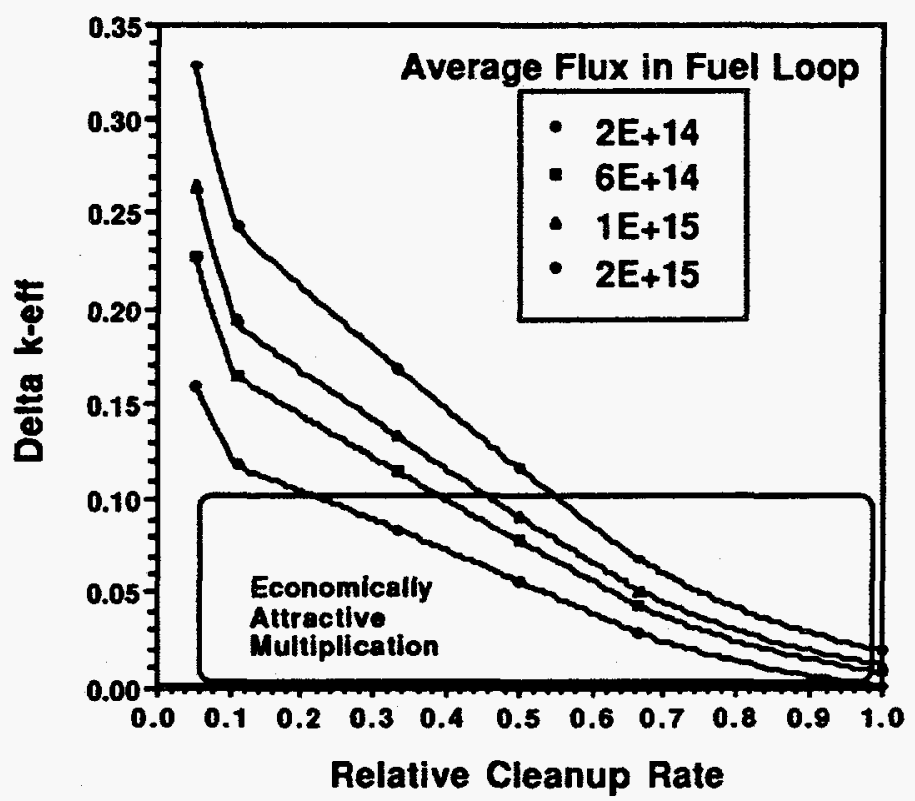

Figure 11: The parameter $\Delta k$ eff calculated at equilibrium for a spent-fuel burning system and a well-moderated thermal spectrum.

\section{A. Impact on Fuel Management and Sensitivity to Feed}

The use of the fluoride salt as the fuel base allows a wide range of feed materials to be put into solution with a minimum of preprocessing. The salt is insensitive to contaminants such as gallium, beryllium, or other metals. The ABC system can accommodate weapon surplus $\mathrm{Pu}$ from any disassembly process without any gallium or contaminant removal. Within the same campaign, lean Pu scrap feed material and contaminated americium feed can be converted through a simple fluorination process into molten salt fuel. The consequences of an incomplete characterization of the makeup feed is diluted in the larger volume of fuel salt in the primary loop. Any resulting perturbation on criticality is tolerable because of the subcritical mode of operation. This description of fuel-feed form flexibility is also relevant to ABC/ATW systems aimed at global plutonium inventory reduction and long-lived waste transmutation.

Solid fuel systems do not have this type of flexibility. Typical solid fuel forms require a complete characterization of the fuel/clad material system. This includes understanding the effect of contaminants on fuel/clad material interactions, complete 
knowledge of the physical properties of the fuel as a function of burnup (i.e., thermal conductivity), and a fuel fabrication process that meets tight specifications for homogeneity, density, and solubility.

\section{B. Performance (Maximum Average Burnup of Discharged Fuell)}

For nuclear reactors in general, redistribution of fuel is required in order to achieve high burnups and involves moving "old fuel" into regions of lower reactivity and "new fuel" into regions of higher reactivity. Fluid fuel systems continuously and inherently redistribute the fuel within the active core region. For solid fuel systems, this must be done physically with penalties for increased accident potential, for additional mechanical structures, and for substantial downtime for shuffling. The extent of burndown is dependent on the resolution of the shuffling scheme; more spatially refined and frequent shuffling leads to higher average discharged fuel burnups in the limit. The buildup of fission products also limits the maximum achievable fuel burnup. Fluid fuel systems using the FCM strategy have lower fissile and radionuclide inventories because of their ability to continuously remove key fission products from the core fuel. Although both the solid fuel and fluid fuel systems are theoretically able to actively remove fission products (by reprocessing), only the fluid fuel system can passively remove key fission products. In comparison, solid fuel reprocessing is batch in nature and requires physical breakdown of the fuel, separation processing, and fuel refabrication.

\section{Hiah-Level Waste Minimization}

The molten salt fuel provides unique features for continuous, passive fission product separation and final cleanup. As the $A B C$ system operates, noble gas fission products such as xenon-135 and krypton-85 leave the salt through a sparging process. Similarly, noble and semi-noble metal fission products can be recovered on specific surfaces or devices within the system. At appropriate stages during operation, these components, relatively small in size, can be removed and treated as high-level metallic radioactive waste. The salt remaining at the end of a campaign can be treated via a precipitation-based separations step so that high-level waste (actinides, fission products, and lanthanides) is recovered and encapsulated in glass. The much larger volume of residual salt can be disposed of as low-level waste. The volumes of highlevel waste arising from the $A B C$ system operation are, therefore, expected to be much less than that from a solid fuel system. The waste stream generated by solid fuel systems consists primarily of spent nuclear fuel assemblies which are comprised of numerous fuel pins that contain the spent fuel and almost all fission products generated during operation. All of this waste is high-level waste destined for geologic disposal.

In summary, the advantages of a molten salt fuel over a solid fuel are significant when the molten salt fuel is used in a FCM campaign strategy. As envisioned, a near total fissile material destruction level can be obtained using the strategy for total burndown described earlier in Section IV. Additionally, a wide variety of fissile materials including americium and neptunium can be used as fuel without any preprocessing to remove contaminants. And finally, waste streams destined for longterm geologic disposal can be significantly smaller than that of a solid fuel system. From a performance perspective, these three attributes point to the attractiveness of the molten salt fuel form. However, in order to take full advantage of the robustness of the FCM strategy in a safe manner, the system must necessarily operate in a subcritical mode as discussed in the preceding sections. 


\section{Conclusions}

This report has quantitatively identified discriminators associated with use of a combined accelerator-fluid fuel (molten salt) system for materials destruction application. A particular focus has been the "value added" by the introduction of an accelerator to a fluid fueled nuclear system. The conclusions of this report are

- Subcritical operation provided by the accelerator is a necessary complement to fluid fuel usage since it provides robust safety margins to variations in system reactivity that can occur via possible insertion mechanisms.

- Subcritical operation is a key requirement in providing neutron economy environments that allow destruction of long-lived fission products so as to significantly reduce long-term dose releases associated with such materials. The degree of subcriticality required to achieve significant decreases in potential dose release is not excessive $\left(\Delta k_{e f f}<0.1\right)$.

- The relaxation of the need to ensure criticality provides flexibility in the operation of systems aimed at material destruction. As an example, the fuel cleanup rate for a waste transmutation system can be decreased by factors approaching ten for a $k_{\text {eff }}$ change of $\mathbf{0 . 1}$.

- The combination of subcritical operation and fluid fuel provides unique capabilities for material burndown because of the flexibility of the system's fuel form and the safely robustness of subcritical operation.

- Fluid fuel provides needed flexibility for a variety of applications involving nuclear material destruction since it removes requirements for materials specification and control associated with solid fuel nuclear systems.

\section{Acknowledgments}

This work was supported by the U. S. Department of Energy's Project for Surplus

Fissile Material Control and Disposition. 


\section{References}

1 "Management and Disposition of Excess Weapons Plutonium," National Academy of Sciences Report, National Academy of Sciences Press, Washington, D. C., 1994.

2 "The Development Status of Molten Salt Breeder Reactors," Oak Ridge National Laboratory report, ORNL-4812, 1972.

3 J. Carson Mark, "Explosive Properties of Reactor Grade Plutonium," Science and Global Security 4, p111, 1993.

4 T. H. Pigford, "Actinide Burning and Waste Disposal," Department of Nuclear Engineering, Berkeley, UCB-NE-4176, Berkeley, CA, 1990.

5 M. Wilson, et al, " Total System Performance for Yucca Mountain - SNL Second Iteration," SAND 93-2675, Sandia National Laboratories, 1994. 


\section{Appendix A}

\section{Potential Reactivity Insertions for Fluid Fuel Plutonium Systems}

A number of potential reactivity insertion mechanisms for a molten salt system are discussed below. All of the numbers presented are representative of an $500 \mathrm{MWT}$ system at beginning of life that has a fuel salt volume of $2 \mathrm{~m}^{3}$. It is likely that the magnitude of most reactivity insertions will decrease as the system changes later in life due to increased plutonium inventory. Therefore, the numbers presented are most likely worst case scenarios. In addition, it should be possible to reduce the effect of some of these insertions by altering the fuel composition or blanket design. The insertions listed apply to both critical and subcritical systems (except for fission product removal). The following discussion is meant to provide insight as to where reactivity insertions may fall on Figures $\mathrm{C}_{2}$ and $\mathrm{C}_{3}$ of Appendix C.

Euel Redistribution: One primary concern in a liquid fuel form system is the possibility of the fuel redistributing in a non-desired manner. There are many mechanisms which could promote redistribution: precipitation due to local saturation, plate out on exposed surfaces, or flow field/buoyancy effects. This effect can be very severe. Our calculations show that if the fuel contained in the top $10 \%$ of the blanket is evenly redistributed in the rest of the blanket, the resulting reactivity insertion is over $\$ 8$.

Fuel Feed Error: The reactivity of a molten salt system is very sensitive to the rate of fuel feed. A large unanticipated increase in the fuel feed can cause a significant reactivity increase. A $500 \mathrm{MWT}$ blanket will have a burnup rate of about $500 \mathrm{~g} /$ day and a fuel feed rate that is somewhat higher. A ten percent fuel feed error (an extra $50 \mathrm{~g}$ of Pu-239) evenly distributed in the blanket region has a worth of $+\$ 1$.

Feed Characterization Error: One of the major advantages of the molten salt system is the ability to process a wide range of nuclear materials. However, this advantage has one negative consequence-the possibility of misidentifying the feed source. In the worst case, high purity Pu-239 fuel could be mistaken for some relatively low-grade fuel. This would result in a reactivity insertion on the order of the fuel feed error described above (in terms of reactivity per excess grams of fuel).

Yoid Collapse: A molten salt system operates with a steady-state level of bubbles in the solution. The void fraction is a function of salt heating and the level of fission product sparging. If the level of salt heating is reduced, or the sparge system becomes inoperative, then the void fraction becomes smaller leading to a reactivity insertion. (Of course, if the sparge system fails, there will also be a gradual increase in fission products, which may offset the reactivity increase due to loss of void.) Our calculations show that a void collapse of $1 \%$ causes a reactivity insertion of about $\$ 2$. However, this magnitude of insertion is not expected because the steady state void fraction should be below $1 \%$.

Eission Product Removal: The molten salt system has on-line fission product removal. If fission product removal stops, then a reactor has to compensate by increasing reactivity. If removal resumes, then there is a net reactivity insertion if the reactor does compensate accordingly. This is not a potential insertion for the subcritical system because, if there is a drop in reactivity, there is no requirement to attempt to compensate (unless the reason for the reactivity drop is fully understood). 
Salt Inlet Temperature: Changes in the temperature of the salt as it enters the blanket can have a significant effect on reactivity, depending on the size and magnitude of the reactivity feedback coefficient. This effect is much larger than for a solid core reactor because, in the molten salt system, the fuel and the coolant are one and the same. A positive coefficient could cause a large insertion if the inlet temperature is increased. If the reactivity temperature coefficient (RTC) was $1.0 \mathrm{E}-4$, then a sustained inlet temperature increase of only $22 \mathrm{~K}$ would cause a $\$ 1$ insertion over a short period of time (a few seconds). A reactivity insertion due to a temperature drop and a negative RTC are of little consequence since the reactor power will quickly respond and cause the temperature to equalize.

Loss of Circulation: During normal operation, a significant percentage of delayed neutrons are emitted outside the blanket. For a residence time of 2.5 seconds inside the blanket and 7.5 seconds outside the blanket, $65 \%$ of the delayed neutrons are lost. This number could be even higher since some of the fission products removed may be delayed neutron precursors. Because of this, the system must have an extra $\$ .65$ of reactivity built in to compensate for delayed neutron loss. In a loss of circulation scenario, these delayed neutrons are regained, resulting in a reactivity insertion of $\$ .65$. However, this insertion is not instantaneous since the 'extra' delayed neutrons are spread out over a period of seconds. In Figures $\mathrm{C} 2$ and $\mathrm{C}_{3}$, this insertion has already been taken into account (i.e., for loss of flow, a reactivity insertion of zero means that there is no insertion except for the $\$ 0.65$ described above). 


\section{Appendix B}

\section{Nuclear Kinetics Analysis for a Molten Salt Plutonium System}

The time dependent response of the molten salt system is obtained with a point kinetics solution. The equations are modified to account for the delayed neutrons that are emitted outside the blanket. The form of the point kinetics equations that is solved is:

$$
\begin{aligned}
d P(t) / d t & =(\rho(t)-\beta) / \Lambda) P(t)+\sum y_{i} \lambda_{i} C_{i}(t)+S(t) \\
d C_{i}(t) / d t & =y_{i}\left(\beta_{i} P(t) / \Lambda-\lambda_{i} C_{i}(t)\right) \\
d T(t) / d t & =a_{1}(t) P(t)+a_{2}(t) P_{0}+a_{3}(t) T(t) \\
\text { where } \rho(t) & =K(t)+\alpha(t) T(t)
\end{aligned}
$$

and

where $y$ is the probability of a precursor emitted at a random position emitting a delayed neutron in the blanket.

In these equations the variables are defined as follows:

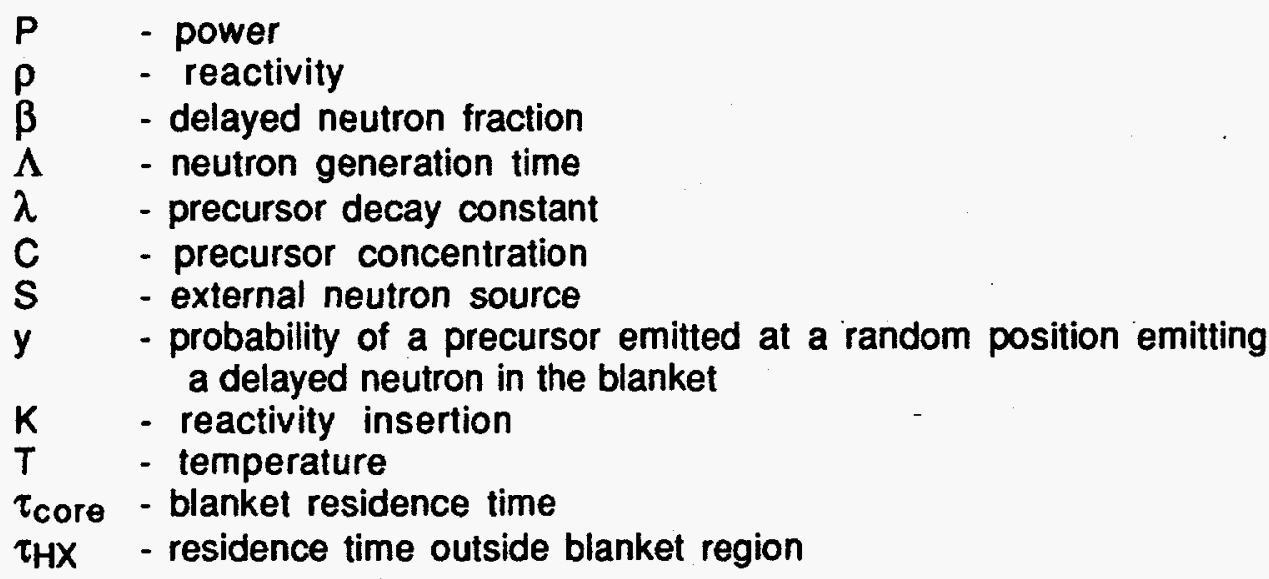

The probability of a precursor "escaping" the blanket on the first pass is:

$$
x 1=1 / \lambda \tau_{\text {core }}\left(1-\exp \left(-\lambda \tau_{\text {core }}\right)\right)
$$

The probability of a precursor surviving the trip through the heat removal system is:

$$
x 2=\exp \left(-\lambda \tau_{H X}\right)
$$

And the probability of a precursor entering the blanket surviving the trip through the blanket is:

$$
\mathrm{X} 3=\exp \left(-\lambda \tau_{\text {core }}\right)
$$


Finally, the total probability of a delayed neutron being emitted in the blanket can be found by combining these individual probabilities and then taking advantage of an exponential expansion (provided $\times 2 \times 3<<1$ ):

$$
y=1-x 1[1-x 2(1-x 3) \exp (\times 2 \times 3)]
$$

In this study, the residence time of the salt was $2.5 \mathrm{~s}$ inside the blanket and $7.5 \mathrm{~s}$ outside the blanket. As a result, only $35 \%$ of the delayed neutrons were retained.

The discrete variables of the equations are found via the Crank-Nicolson method, and the resulting set of equations is solved by a direct solver. The equations are placed in a square matrix in such a way that the set of equations can be represented as four vectors. The matrix can then be easily solved with a small number of calculations. The error is approximated by including the effect of an additional term in the Taylor expansion, and the time step is adjusted accordingly.

All fissions are assumed to be from $\mathrm{Pu}-239$, with a delayed neutron fraction of 0.00212 . The delayed neutrons are represented by six precursor groups. The neutron generation time is assumed to be $1.0 \mathrm{E}-4$ seconds. The steady state source and precursor concentrations are calculated based on the initial power.

A simple heat transfer solution is obtained based on the specific heat and volume of the salt and the heat removal rate. In this study, three cases are considered: constant heat removal, adiabatic heatup of the entire salt inventory (loss of heat removal system), and adiabatic heatup of the salt in the blanket (loss of flow).

A large number of kinetics solutions were obtained for a $500 \mathrm{MW}(\mathrm{t})$ molten salt plutonium system with a blanket salt volume of $2 \mathrm{~m}^{3}$, a total salt volume of $8 \mathrm{~m}^{3}$, and an operating temperature of $900 \mathrm{~K}$. The parameters varied were magnitude of reactivity insertion, operating keff, temperature reactivity coefficient, and the heat transfer mode. For each solution, the time-dependent power, reactivity, and temperature are obtained.

The key result of each kinetics solution is the time at which the salt reaches $1500 \mathrm{~K}$. This represents how long a time period is available to initiate mitigating actions without suffering severe consequences. To simplify and reduce the amount of data presented in this report, this is the only parameter presented for each case. 


\section{Appendix C}

\section{Accident Response of Molten Salt Systems}

The primary discriminator between a critical and subcritical system is how the systems respond to reactivity insertions. In order to demonstrate the advantage of the subcritical assembly, the nuclear kinetics model described in Appendix B was used to assess several different accident scenarios. There are three different cooling scenarios considered: constant heat removal (heat is removed at the steady state rate), loss of heat removal system (the salt continues to flow through the blanket, but no heat is removed), and loss of flow (the salt is stagnant in the blanket due to a blockage or loss of primary pumps). For each cooling scenario, a point kinetics solution was obtained for a wide range of reactivity insertions and operating eigenvalues. The primary result of each of these solutions is the time at which the salt reaches $1500 \mathrm{~K}$ if no action is taken (either a control rod scram or accelerator shutoff). Figure $\mathrm{C}_{1}$ illustrates an example of a time-dependent result obtained for the case of a $\$ 5$ reactivity insertion $(\Delta k / k$ of 0.01$)$ and for the case of a reactivity temperature coefficient having a null slope. This information was obtained for a large number of reactivity insertion cases, and results are plotted for a positive and negative temperature coefficient in Figures $\mathrm{C}_{2}$ and $\mathrm{C} 3$. Results for a null reactivity temperature coefficient (RTC) were presented in Figure 2 in the main body of the report.

Constant Power Removal $500 \mathrm{MW}$

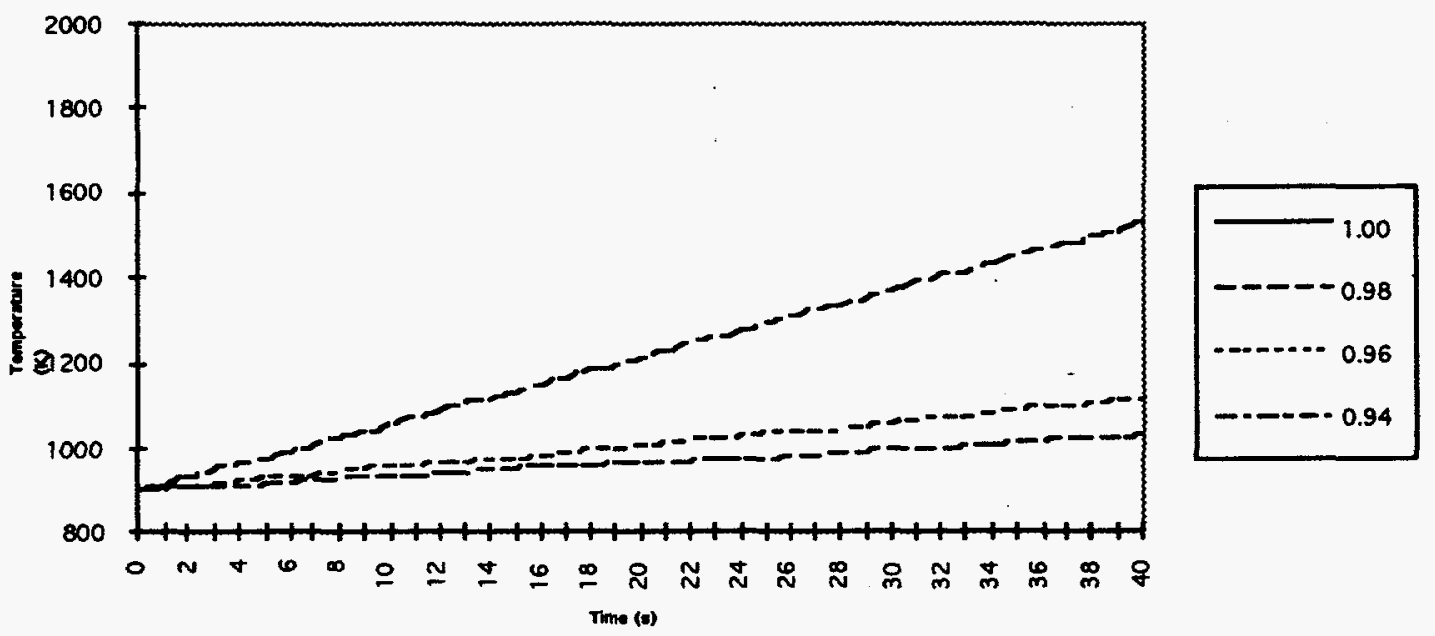

Figure C1: Time-dependent system response to a $\$ 5$ reactivity insertion under the assumption of a null reactivity temperature coefficient behavior. Line types used for $k_{\text {eff }}$ values of $1.0,0.98,0.96$, and 0.94 are shown on the right. The time response for $k_{\text {eff }}$ equal to one is zero (lies on top of the ordinate).

In each of these three cases involving subcritical operation, the accelerator source of neutrons is still considered to be operational even though in all present acceleratorbased systems, interlocks with key system components prevent accelerator operation under off-normal conditions. This comparison is overly conservative and unlikely. 
The rapid shutoff time (10s of milliseconds) for the accelerator is orders of magnitude smaller than the very conservative response times shown in Figure $\mathrm{C} 1$ and C2.

Figure $\mathrm{C} 2$ shows the accident response assuming a constant negative coefficient. For constant heat removal, the subcritical system is superior for all reactivity insertions. When loss of heat removal and loss of flow are considered, the subcritical assembly is superior for large insertions. For the keff=1 (reactor) case, the passive shutdown mode prevents reaching the temperature limit of $1500 \mathrm{~K}$ for insertions less than $\$ 3$ ( $\$ 2$ in the loss-of-flow case).

Figure C3 contains the results for a constant positive RTC. Here the subcritical assembly holds a major advantage over the reactor. This is especially evident in the loss of heat removal and loss of flow cases, where the reactor will suffer serious consequences in a fraction of a second regardless of whether there is a reactivity insertion or not.

The results presented in Figures $\mathrm{C} 2$ and $\mathrm{C} 3$ (as well as Figure 2 in the main body of the report) show the inherent safety advantages of a subcritical system. Since accelerator shutoff is easier than control rod scram, the subcritical system is safer than the critical system even under the very unlikely scenario assumed for the accelerator system in these comparisons. In addition, these response times are conservative since the model assumes adiabatic heatup of the salt. The effects of pump coast down and passive heat removal will cause response times to be even longer (except in prompt critical scenarios), thus giving the sub-critical system even more of an advantage. Even in the best of scenarios, the critical system is unable to tolerate any reactivity insertion over $\$ 3$. The magnitude of possible insertions was summarized in the main portion of the report and in Appendix $A$. 
Constant Heat Removal

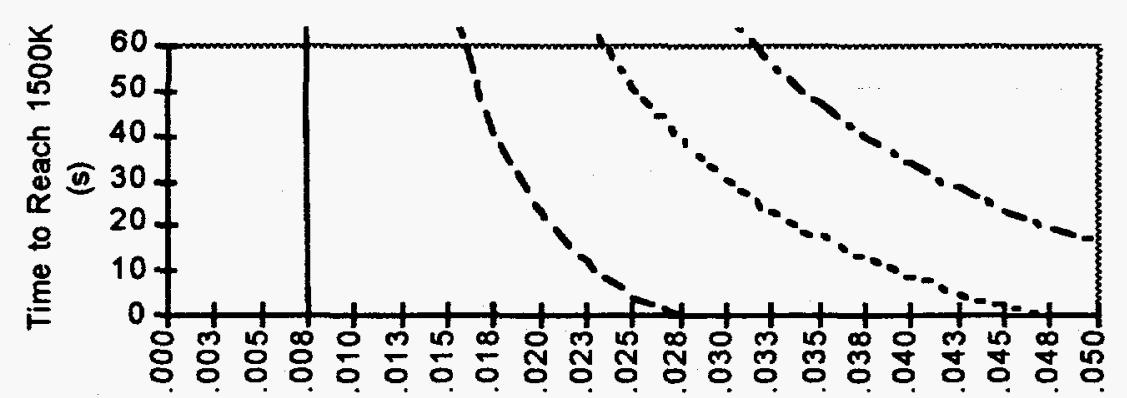

Reactivity Insertion $(.00212=\$ 1)$

\section{Loss of Heat Removal System}

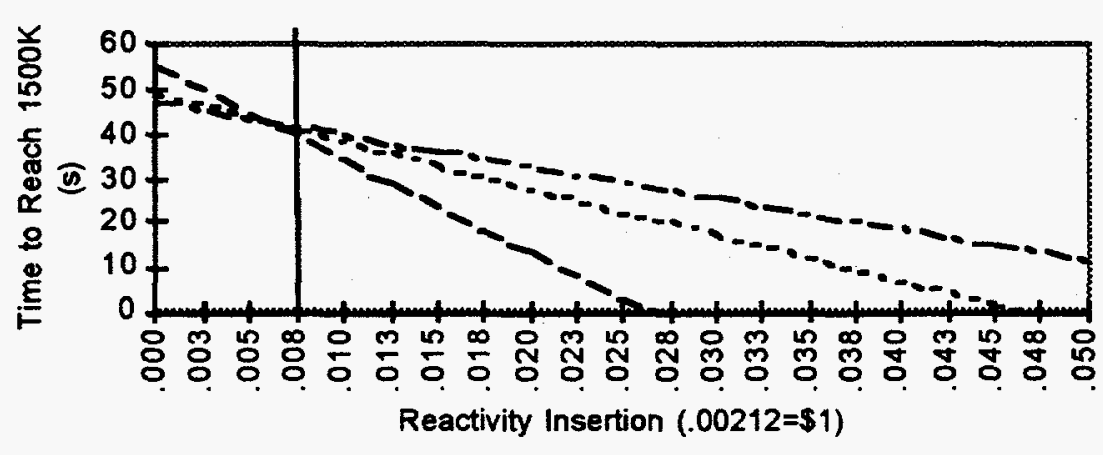

\section{Loss of Pumps (No Flow)}

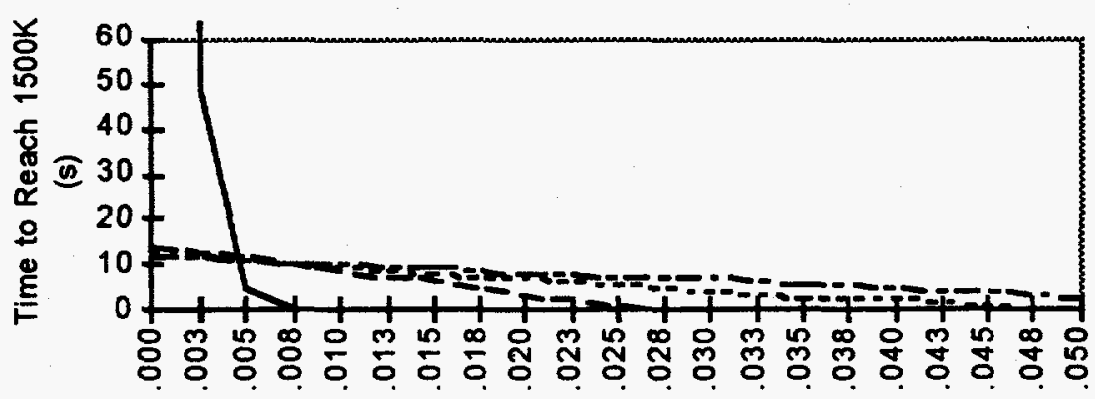

Reactivity Insertion $(.00212=\$ 1)$ k-eff

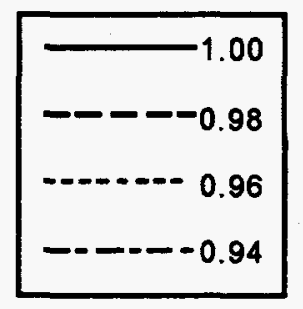

k-eff

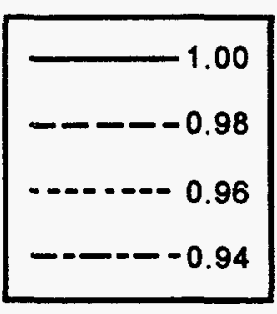

Figure C2: Accident response of $500 \mathrm{MW}$ molten-salt plutonium system with constant negative isothermal reactivity temperature coefficient $(-2.0 E-05)$. 
Constant Heat Removal

k-eff
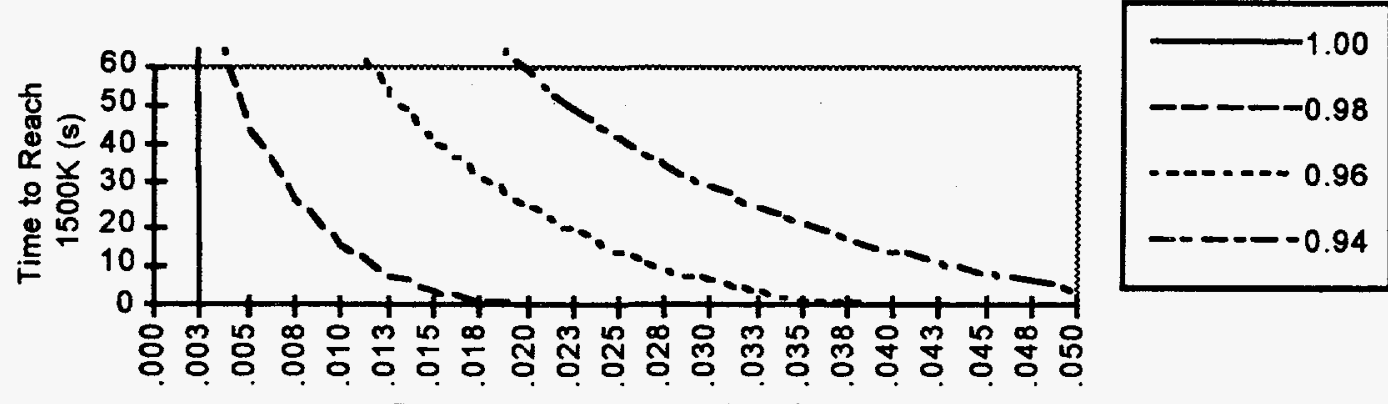

Reactivity Insertion $(.00212=\$ 1)$

Loss of Heat Removal System

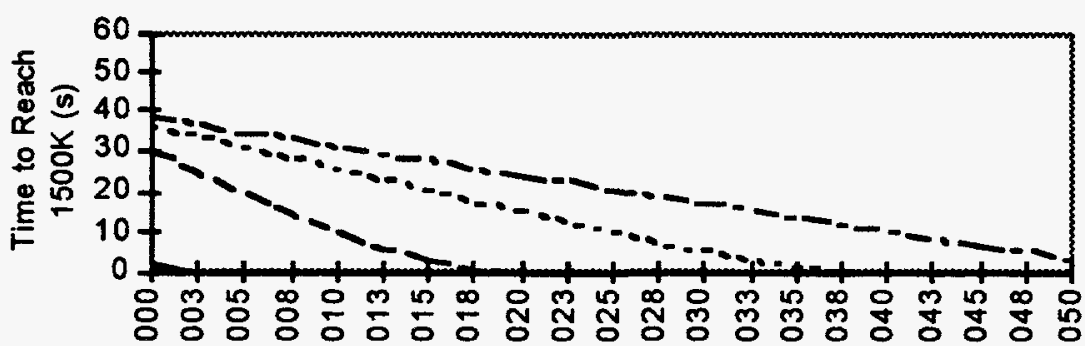

k-eff

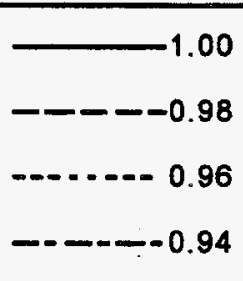

Reactivity Insertion (.00212=\$1)

Loss of Pumps (No Flow)

k-eff

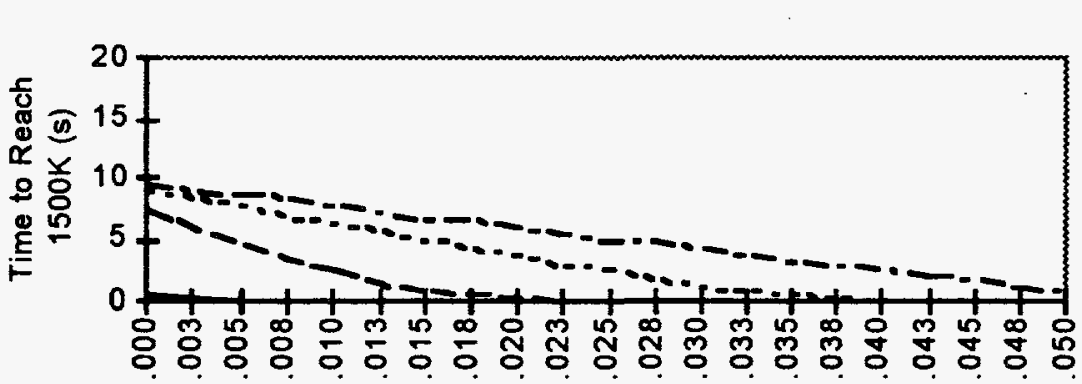

1.00

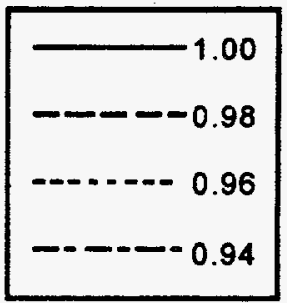

Reactivity Insertion (.00212=\$1)

Figure C3: Accident response of $500 \mathrm{MW}(t)$ molten-salt plutonium system with constant positive isothermal reactivity temperature coefficient $(+2.0 E-05)$. 
Appendix D

\section{Application of Highly Enriched Uranium (HEU) Fuel to Accelerator- Driven Plutonium Burndown}

The use of this mode of operation in a subcritical molten salt nuclear system to achieve extremely large destruction values for plutonium was discussed in Section $V$ of the main report. This Appendix provides supplemental information about the parameters and assumptions used in the analysis, plus additional results. An accelerator-driven system for elimination of weapons plutonium offers, in addition to high Pu burnup per initial burn cycle $(\sim 89 \%)$, the potential for almost complete Pu burnup ( $99 \%$ ) in an highly enriched uranium (HEU) fueled burndown mode. An accelerator-driven system is extremely robust with respect to a change in fuel feed (to the molten salt) from weapons-grade plutonium to HEU. An example of the HEU-fueled burndown has been analyzed for a reference 500-MW target-blanket module (Table D1).

Table D1: Accelerator-driven reference target-blanket module for burning of weapons plutonium

\begin{tabular}{|l|c|}
\hline Power (MWth-fission) & 500 \\
\hline Blanket Salt Volume Fraction (\%) & 10 \\
\hline Salt Inventory $\left(\mathrm{m}^{3}\right)$ & 16.6 \\
\hline Blanket $\left(\mathrm{m}^{3}\right)$ & 7.6 \\
\hline Plenna $\left(\mathrm{m}^{3}\right)$ & 3.0 \\
\hline HX Salt $\left(\mathrm{m}^{3}\right)$ & 6.0 \\
\hline Keff & 0.96 \\
\hline Noble Gas Removal $(\mathrm{s})$ & 50 \\
\hline Noble Metal Removal $(\mathrm{h})$ & 2.4 \\
\hline
\end{tabular}

The plutonium burn strategy was assumed to be a two-phase operation in which the first phase is a weapons-plutonium-fueled power production cycle whose length $(\sim 10$ years) is determined by salt solubility limits for the actinides ( $P u$ through $\mathrm{Cm}$ ) and the fission-product lanthanides. Following this cycle, the salt is cooled ( $1-10$ years), and the residual plutonium $(\sim 250 \mathrm{~kg})$ is recovered. The second phase is a HEU-fueled (with residual $\mathrm{Pu}$ ) power production cycle whose length ( 3-5 years) is determined by maximum $\mathrm{Pu}$ burndown requirements. For calculational simplicity, the initial fuel feed in Phase 2 is assumed to be only residual Pu until the $250 \mathrm{~kg}$ inventory is depleted ( 3 months). This two-phase burn strategy is summarized in Table D2.

The calculated plutonium burnup performance in Phase 2 was presented in Figure 4 of the main report. Shortly after the introduction of the HEU fuel $(\sim 1$ year), the Pu-239 burnup approaches a maximum. 
Table D2: Two-phase strategy for accelerator-driven burning of weapons plutonium

\section{Phase 1}

- Feed WPu maintaining keff $=.96$ and $P_{t h}=500 \mathrm{MW}$ until Actinide + Lanthanide concentration limit $(0.3 \mathrm{~m} / \mathrm{l})$ reached $\simeq 10$ years

- Cool and then clean up salt and recover Pu left at EOL $(250 \mathrm{~kg})$ $\sim 5-10$ years

Phase 2A

- Feed EOL Pu maintaining keff=.96 and $P_{t h}=500 \mathrm{MW}$ until stock $(250 \mathrm{~kg}$ ) is depleted $\sim 3$ months

Phase 2B

- Feed HEU maintaining keff=.96 and $P_{t h}=500 \mathrm{MW}$ until $\mathrm{Pu}$ burnup is maximized $\sim 5$ years

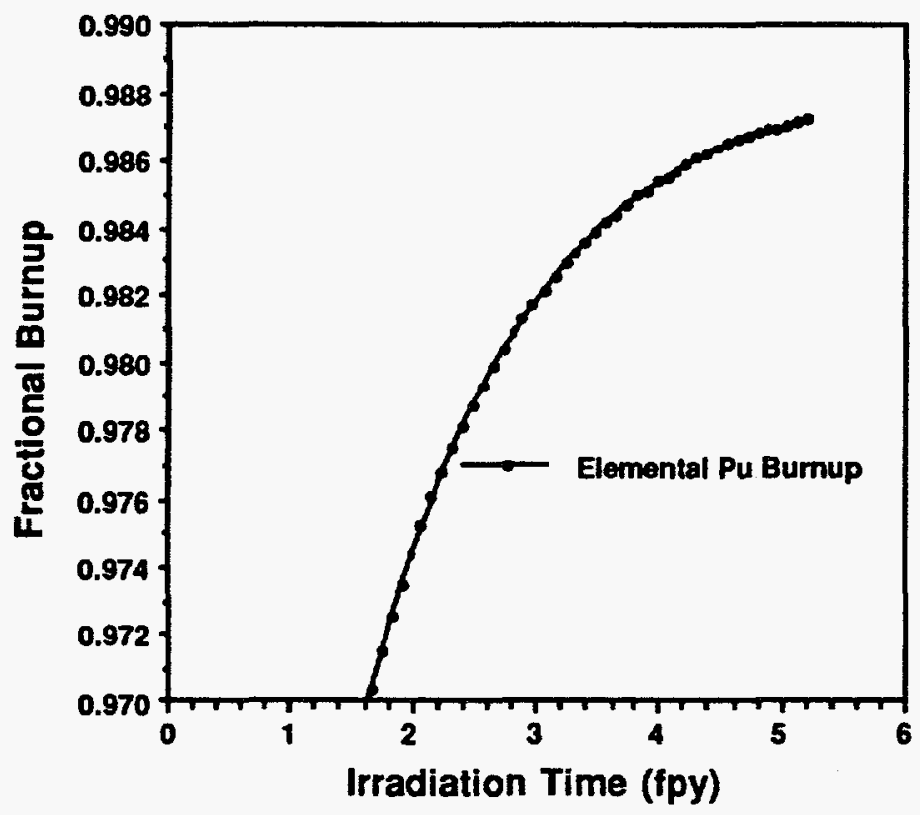

Figure D1: Elemental plutonium fractional burnup calculated during Phase 2 burndown. 


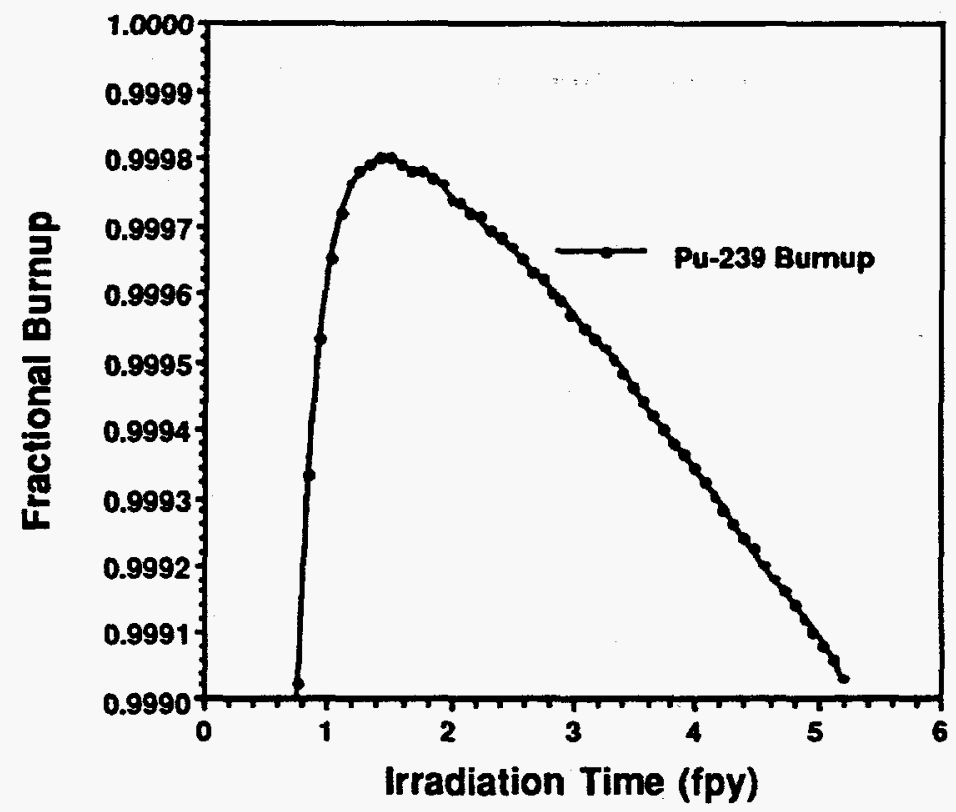

Figure D2: Pu-239 fractional burnup calculated during Phase 2 burndown.

The calculated elemental plutonium fractional burnup closely approaches the maximum ( 98.8 to $99 \%$ ) in Phase 2 , but additional burnup may not be productive or necessary. The Pu-239 fractional burnup (shown in Figure D2) indicates that the production of $\mathrm{Pu}-239$ from capture in uranium sets an upper limit on the Pu-239 fractional burnup of $\sim 99.98 \%$ for an HEU-fueled system. 


\section{Appendix $E$}

\section{Methodology for Calculating Relative Doses for Radionuclides Released to the Accessible Environment}

If complete and instantaneous failure of the engineered barrier (e.g., waste canister) in a geologic repository occurs at time $t_{E}$ after emplacement, the amount of radionuclide species $i, l_{i}$, available at that time to enter groundwater which may have intruded into the repository is given by:

$$
I_{i}^{E}=I_{i}^{0} e^{-\lambda_{1} t_{E}}
$$

where

$i_{i}$ is the total initial inventory (nuclides) of radionuclide $i$ in the repository,

$\lambda_{i}$ is the decay constant for radionuclide $i\left(\sec ^{-1}\right)$, and

$t_{E}$ is the time at which the engineered barrier (e.g., waste canister) fails (sec).

The rate at which a radionuclide i enters groundwater within the repository at postfailure time $t \leq$ after the failure of the engineered barrier $R_{i}(t \leq)$ (nuclides/second) is given by

$$
R_{i}^{E}\left(t^{\prime \prime}\right)=l_{i}^{0} e^{-\lambda_{1} t_{E}} f_{i} e^{-\lambda_{i} t^{\prime \prime}} \quad\left(t_{E}<t<<t_{E}+t_{D i}\right)
$$

where

$f_{i}$ is the fractional dissolution rate of radionuclide $i$ in ground water $\left(\sec ^{-1}\right)$,

$t \leq\left(t \leq=t-t_{E}\right)$ is the time after failure of the engineered barrier (sec).

The value of $f_{i}$ is given by $1 / t_{D i}$ where $t_{D i}$ is the total dissolution time for species $i$. The water solubility of species $i$ (in its preferred chemical form) and groundwater exposure rates are two of the most important parameters determining t $\mathrm{Di}$. 
During the transport of the radionuclide in the ground water, decay and sorption on the geologic media decrease the amount available for release to the biosphere. Thus, the release rate (nuclides/second) at post-release time $t^{\prime}$ of radionuclide ifrom a geologic repository $R_{i}^{R}\left(t^{\circ}\right)$ can be expressed as

$$
R_{i}^{R}\left(t^{\prime}\right)=I_{i}^{0} e^{-\lambda_{1} t_{E}} f_{i} e^{-\lambda_{i} K_{i} t_{W}} e^{-\lambda_{i} t^{\prime}} \quad\left(t_{E}+t_{W}<t^{\prime}<t_{E}+t_{W}+t_{D i}\right)
$$

where

tw is the groundwater travel time to the accessible environment (sec),

$K_{i}$ is the retardation factor for radionuclide $i$ (unitless), and

$t^{\prime}\left(t^{*}=t-t_{E}-t_{W}\right)$ is the time after radionuclide i begins reaching accessible environment (sec).

At post-release times greater than the sum of the dissolution time plus the water travel time (tw+t $\left.{ }^{\prime}\right)$, the release rate $R_{i}^{R}\left(t^{\circ}\right)$ is zero.

The total amount of radionuclide $i$ (nuclides) in the accessible environment $\mathrm{l}_{i}\left(\mathrm{t}^{\prime}\right)$ at post-release time $t^{\prime}\left(t_{E}+t_{W}<t^{\prime}<t_{E}+t_{W}+t_{D i}\right)$ is given by the solution to the equation

$$
\frac{d\left[l_{i}\left(t^{\prime}\right)\right]}{d t^{\prime}}=R_{i}^{R}\left(t^{\prime}\right)-\lambda_{i} I_{i}\left(t^{\prime}\right)
$$

The solution to Eq. E.4 is

$$
I_{i}\left(t^{\prime}\right)=l_{i}^{0} e^{-\lambda_{i} t_{E}} f_{i} e^{-\lambda_{1} K_{i} t_{w}} t^{\prime} e^{-\lambda_{1} t^{\prime}}
$$

Similarly, at post-release time $t^{\prime}\left(t^{\prime}>t_{E}+t W+t_{D}\right), l_{i}\left(t^{\circ}\right)$ is given by

$$
I_{i}\left(t^{\prime}\right)=I_{i}^{R} e^{-\lambda_{i} t^{\prime}}
$$

The parameter $R_{i}^{R}$ is the total amount of radionuclide $i$ in the accessible environment at the time the release of that species is complete. It is given by

$$
l_{i}^{R}=l_{i}^{0} e^{-\lambda_{i} t_{E}} f_{i} e^{-\lambda_{i} K_{i} t_{w}} t_{D i} e^{-\lambda_{1} t_{D I}}
$$


A volume $\left(\mathrm{m}^{3}\right)$, of water $v \mathrm{~d}_{i}$, which represents the dilution (and dispersion) of radionuclide $i$ at release $(t=t E+t w)$ to the biosphere, is used to calculate the concentration of species $i$ in contaminated water in the accessible environment. No further dilution is assumed beyond time, and thus, calculated concentrations represent upper bounds. The total number of decays or disintegrations per unit volume (dis $/ \mathrm{m}^{3}$ ) of contaminated water in the accessible environment at "reference" post-release time $t^{\prime}=t_{R}$ due to radionuclide $i, r_{i}\left(t_{R}\right)$, is given by

$$
r_{i}\left(t_{R}\right)=\int_{0}^{t_{R}} \frac{\lambda_{i} l_{i}\left(t^{\prime}\right)}{v_{i}^{d}}
$$

For $t_{R}<t_{D i}$ and $t_{R}>t_{D i}$, Eq. E.8 becomes, respectively,

$$
\begin{aligned}
& r_{i}\left(t_{R}\right)=\frac{\lambda_{i}}{V^{d}} I_{i}^{0} e^{-\lambda_{1} t_{E} f_{i}} e^{-\lambda_{i} K_{i} t_{w}} \int_{0}^{t_{R}} t^{\prime} e^{-\lambda_{i} t^{\prime}} d t^{\prime} \quad t_{R}<t_{D i} \\
& =\frac{\lambda_{i}}{V_{i}^{d}} I_{i}^{0} e^{-\lambda_{i} t_{E}} f_{i} e^{-\lambda_{i} K_{i} t_{W}}\left[\int_{0}^{t_{D i}} t^{\prime} e^{-\lambda_{i} t^{\prime}} d t^{\prime}+\int_{t_{D i}}^{t_{R}} t_{D i} e^{-\lambda_{i} t^{\prime}} d t^{\prime}\right] \quad t_{R}>t_{D i}
\end{aligned}
$$

The analytic solution to Eq. E.9 is given by

$$
\begin{aligned}
r_{i}\left(t_{R}\right) & =\frac{l_{i}^{0}}{\lambda_{i} V_{i}^{d}} e^{-\lambda_{i} t_{E}} f_{i} e^{-\lambda_{i} K_{i} t_{w}}\left[1-e^{-\lambda_{i} t_{A}}-\lambda_{i} t_{R} e^{-\lambda_{i} t_{R}}\right] & t_{R}<t_{D i} \\
& =\frac{l_{i}^{0}}{\lambda V^{d}} e^{-\lambda_{i} t_{E}} f_{i} e^{-\lambda_{i} K_{i} t_{w}}\left[1-e^{-\lambda_{i} t_{D i}}-\lambda_{i} t_{D i} e^{-\lambda_{i} t_{F}}\right] & t_{R}>t_{D i}
\end{aligned}
$$

These expressions can be simplified to give

$$
r_{i}\left(t_{R}\right)=\frac{1}{\lambda_{i}} \beta_{i}\left(t_{E}\right) \gamma_{i}\left(t_{w}\right) \delta_{i}\left(t_{R}\right) l_{i}^{0}
$$

where

$$
\begin{aligned}
& \beta_{i}\left(t_{E}\right)=f_{i} e^{-\lambda_{i} t_{E}} \quad, \\
& \gamma_{i}\left(t_{w}\right)=\frac{e^{-\lambda_{1} K_{i} t_{w}}}{V_{i}^{d_{i}}} \quad \text {, and } \\
& \delta_{i}\left(t_{R}\right)=1-e^{-\lambda_{i} t_{R}}-\lambda_{i} t_{R} e^{-\lambda_{i} t_{R}} \quad t_{R}<t_{D i} \\
& =1-e^{-\lambda_{i} t_{D i}}-\lambda_{i} t_{D i} e^{-\lambda_{i} t_{R}} \quad t_{R}>t_{D i}
\end{aligned}
$$


The total integrated dose due to continuous exposure to contaminated water at the accessible environment at reference post-release time $t_{R}$ due to radionuclide $i D_{i}\left(t_{R}\right)$ (rems) is simply

$$
D_{i}\left(t_{R}\right)=c_{i} r_{i}\left(t_{R}\right)
$$

where

$c_{i}$ is the dose conversion factor for radionuclide $i\left(r e m\right.$ per $\mathrm{dis} / \mathrm{m}^{3}$ ).

If Eqs. E.11 and E.15 are combined, the resulting expression is

$$
D_{i}\left(t_{R}\right)=\frac{c_{i}}{\lambda_{i}} \beta_{f}\left(t_{E}\right) \gamma_{i}\left(t_{w}\right) \delta_{(}\left(t_{F}\right) l_{i}^{0}
$$

The values of the radionuclide-dependent parameters for the seven LLFPs are given in Table E1. The values of $f_{i}$ and $K_{i}$ for Tc-99, 1-129, and Cs-135 were taken from a paper by Pigford ${ }^{4}$ which focused on these three radionuclides (in addition to the actinides) because of their large solubilities in water. The values of $f j$ for the other four LLFPs were taken to be the same as that for highly soluble Tc-99 while the values of $K_{i}$ were assumed to be those of highly mobile $1-129$. The values represent very conservative assumptions for Se-79, $\mathrm{Zr}-93, \mathrm{Pd}-107$, and $\mathrm{Sn}-126$ release. Note that values of the parameter $V d_{i}$ are not available, and subsequent development of this methodology assumes that the ratio of this parameter for any two LLFP species is approximately equal to 1.0 based on Pigford's paper.

Table E1: Representative radionuclide-dependent parameters for the integrated dose

\begin{tabular}{|c|c|c|c|c|}
\hline & $(g-a / M T H M)$ & $\lambda_{i}\left(\sec ^{-1}\right)$ & $f_{i}\left(\sec ^{-1}\right)$ & $K_{i}$ \\
\hline $\mathrm{Se}-79$ & $7.43 E-02$ & $3.38 E-13$ & $7.92 \mathrm{E}-12^{*}$ & $1.00 E+00 t$ \\
\hline$\overline{Z r-93}$ & $7.73 E+00$ & $1.46 E-14$ & $7.92 E-12^{\star}$ & $1.00 \mathrm{E}+00 t$ \\
\hline Tc-99 & $7.79 E+00$ & $1.03 E-13$ & $7.92 E-12$ & $1.60 E+00$ \\
\hline Pd-107 & $2.04 E+00$ & $3.38 E-15$ & $7.92 \mathrm{E}-12^{*}$ & $1.00 \mathrm{E}+00 t$ \\
\hline Sn-126 & $2.17 E-01$ & $2.20 E-13$ & $7.92 E-12^{\star}$ & $1.00 \mathrm{E}+00 t$ \\
\hline $1-129$ & $1.39 E+00$ & $1.40 E-15$ & $7.92 E-12$ & $1.00 E+00$ \\
\hline Cs-135 & $2.22 E+00$ & $9.55 E-15$ & $7.92 E-12$ & $6.10 E+02$ \\
\hline
\end{tabular}
model with data from Pigford.

The dose conversion factor $c_{j}$ used in this analysis is calculated as the absorbed dose in an infinite volume of water per unit concentration of radionuclide species $i$. The average energy per decay includes beta and gamma energies of parent and daughters assuming a relative biological effectiveness (RBE) of 1.0. Biological consolidation or retention is not included. The dose conversion factors used for the LLFPs are presented in Table E2. 
Table E2: Dose conversion factors based on total absorbed decay energy in an infinite volume of water.

\begin{tabular}{|c|c|c|l|}
\hline LLFP & $\begin{array}{c}\mathrm{C}_{\mathrm{i}} \\
\left.\text { (rem per dis } / \mathrm{m}^{3}\right)\end{array}$ & $\begin{array}{c}\mathrm{E}_{\mathrm{avg}} \\
(\mathrm{MeV})\end{array}$ & $\begin{array}{c}\text { Contributing } \\
\text { Daughters }\end{array}$ \\
\hline $\mathrm{Se}-79$ & $8.55 \mathrm{E}-16$ & 0.0533 & None \\
\hline $\mathrm{Zr}-93$ & $8.08 \mathrm{E}-16$ & 0.0504 & Nb-93m \\
\hline $\mathrm{Tc}-99$ & $1.56 \mathrm{E}-15$ & 0.0973 & None \\
\hline $\mathrm{Pd}-107$ & $2.14 \mathrm{E}-16$ & 0.0133 & None \\
\hline $\mathrm{Sn}-126$ & $4.34 \mathrm{E}-14$ & 2.7074 & $\begin{array}{l}\text { Sb-126m, } \\
\text { Sb-126 }\end{array}$ \\
\hline $\mathrm{I}-129$ & $1.40 \mathrm{E}-15$ & 0.0876 & None \\
\hline $\mathrm{Cs}-135$ & $1.12 \mathrm{E}-15$ & 0.0700 & None \\
\hline
\end{tabular}

In order to assess relative dose, the ratio of total integrated dose $D_{i}\left(t_{R}\right)$ to that for a reference LLFP species $j$ (e.g., Tc-99) is defined. This ratio $H_{i T_{c}}\left(t_{R}\right)$ is a measure of the relative benefit of management of other LLFPs compared to TC-99. The ratio is given by

$$
H_{i j}\left(t_{R}\right)=\frac{c_{i} \beta_{i}\left(t_{E}\right) \gamma_{i}\left(t_{w}\right) \delta_{f}\left(t_{R}\right)}{c_{j} \beta_{j}\left(t_{E}\right) \gamma_{j}\left(t_{w}\right) \delta_{j}\left(t_{R}\right)} \frac{\lambda_{j}}{\lambda_{i}} \frac{l_{i}^{0}}{l_{j}^{0}} .
$$

Species for which decay daughter chains, particularly the actinides, are large contributors to the total dose assigned to the original precursor do not lend themselves to this treatment. For LLFPs with a single significant daughter in equilibrium (e.g., Sb-126 with Sn-126 and Nb-93m with Zr-93), $c_{i}$ (Table E2) accounts for the dose multiplier associated with the daughter.

Pigford 4 defined a similar "relative dose index" parameter as a measure of the dose rate of a released radionuclide species relative to that of the dominant LLFP species TC-99; the dose rate was taken at the boundary to the biosphere and at the time of initial release. The parameter accounts for both decay and sorption on rock as the species migrate from the repository and thus is a function of the water travel time to the biosphere boundary. The "relative dose index" has the form

$$
\frac{D_{i}}{D_{j}}=\frac{M_{j} f_{i} e^{-\lambda_{i} K_{i} t_{w}} C_{i} W_{i}}{M_{j} f_{j} e^{-\lambda_{j} K_{j} t_{w}} C_{j} W_{j}}
$$

where $f_{i}, t_{W}$, and $K_{i}$ are defined as above and

$D_{i}$ is a dose rate contribution (rem/yr) from radionuclide species $i$,

$M_{i}$ is the inventory $(\mathrm{Ci})$ of radionuclide species i emplaced in the repository,

$C_{i}$ is a dose conversion factor ( average rem/yr per $\mathrm{Ci} / \mathrm{m}^{3}$ in $\mathrm{H}_{2} \mathrm{O}$ ) from radionuclide species $\mathrm{i}$, and

$W_{i}$ is a dilution/dispersion rate $\left(\mathrm{m}^{3} / \mathrm{yr}\right)$ of radionuclide species $i$ as it migrates to the biosphere. 
This ratio is a measure of the relative dose rates of radionuclide species at the boundary to the biosphere and at the time of initial release. It does not reflect either the time-dependent dose rate or integral dose.

Pigford used the "relative dose index" in a recent assessment of the impact of actinide and fission product transmutation on waste repository performance 4 to show that some of the LLFPs were much more significant dose contributors to the biosphere in releases from a repository than the major actinides. These results were largely based on the high solubilities of the these LLFPs with respect to the actinides. The actinide solubilities used by Pigford were based on actinide metals; however, recent Yucca Mountain performance assessments ${ }^{5}$ recognize that the oxide solubilities are the relevant values. These values are from $10^{3}$ to $10^{5}$ larger than those use by Pigford (see Table E3).

Table E3: Actinide Solubilities (moles/liter) Assumed for Repository Assessments

\begin{tabular}{|c|c|c|}
\hline Material & 1991 Value & 1993 Value \\
\hline Uranium & $10^{-7.7}$ & $10^{-4.5}$ \\
\hline Neptunium & $10^{-9}$ & $10^{-4}$ \\
\hline Plutonium & $10^{-12.4}$ & $10^{-7}$ \\
\hline Americium & $10^{-8.2}$ & $10^{-7}$ \\
\hline
\end{tabular}

If Pigford's "relative dose index" methodology is modified for these more recent actinide solubilities, the actinides become larger contributors to the repository release dose, but the LLFPs still remain as equally significant contributors. The results of this modification to the Pigford analyses are presented in Figure E1.

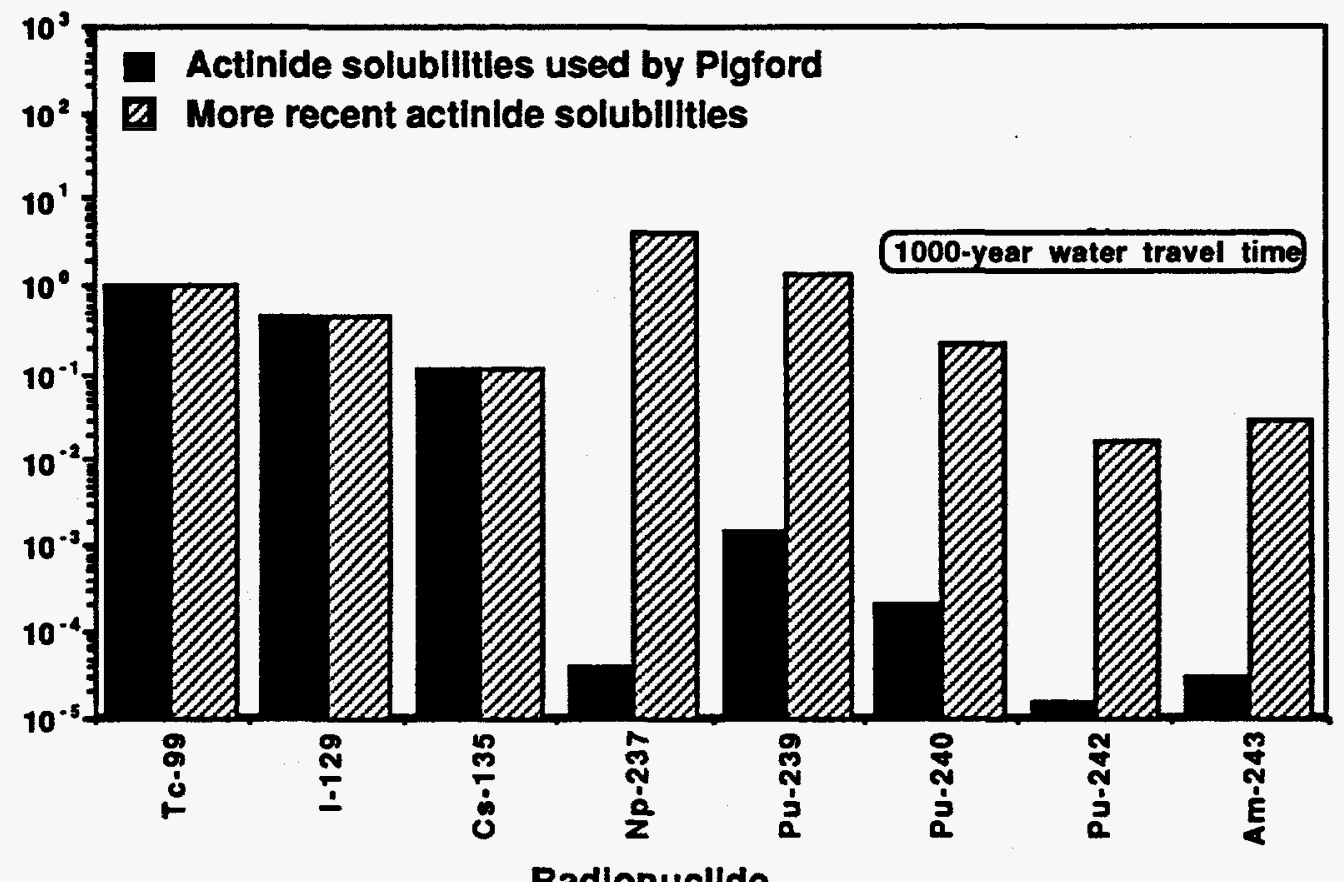

Figure E1: Relative Dose Index for repository release (and a water travel time of 1000 years) of dominant actinides and LLFPs calculated by Pigford and modified for newer actinide solubilities. 


\section{Appendix F}

Contributions to Reactivity in an Accelerator-Driven Subcritical Transmutation System

For a system fission power $P_{f}$ expressed in fissions per second, the accelerator beam current requirement $\mathrm{lb}$ expressed in protons per second is given by

$$
I_{b}=\frac{P_{f} \nabla}{y_{n / p} M_{S}}
$$

where

$v$ is the average number of neutrons liberated per fission,

$y_{n / p}$ is the net spallation target yield (neutrons/proton), and

$M_{S}$ is the system source neutron multiplication.

The source neutron multiplication $M_{S}$ is given by

$$
M_{S}=\frac{k_{\text {eff }}}{1-k_{\text {eff }}}
$$

where $k_{\text {eff }}$ is the fission multiplication factor for the system and can be expressed as

$$
k_{\text {eff }}=\frac{\nabla p_{N L}}{1+\alpha_{F}+\alpha_{S / T}+\alpha_{F P}+\alpha_{L L}}
$$

where

$v \quad$ is the number of neutrons produced per fission,

PNL is the system neutron non-leakage probability,

$\alpha_{F} \quad$ is the number of system neutron captures in the fuel per fission in the fuel,

$\alpha S / T$ is the number of system neutron captures in the structure and target per fission in the fuel,

QFP is the number of system neutron captures in the parasitic fission products per fission in the fuel, and

$\alpha_{\mathrm{LL}} \quad$ is the number of system neutron captures in the long-lived fission products per fission in the fuel. 
The parameters in this expression are system values and can either describe the neutron economy in replicated, multi-function target-blanket module or averaged over target-blanket systems with different functions (e.g., plutonium burning, LLFP transmutation, etc.). The parameter $\alpha F$ is characteristic of the nuclear fuel and spectrum while $\alpha_{S / T}$ is strongly dependent on the target-blanket design(s). The parameters $\alpha_{F P}$ and $\alpha_{\mathrm{LL}}$ are determined by the fuel processing scheme and longlived fission product transmutation strategy, respectively.

\section{A Contribution of Parasitic Fission Product Absorption to Reactivity}

The parameter afp is determined by the fission product cross sections and the relative rates of fission product species production from fission and recovery in processing. It varies as

where

$$
\alpha_{\mathrm{FP}} \propto \phi \tau \sigma_{\mathrm{FP}}^{\mathrm{a}}
$$

$\phi \quad$ is the average neutron flux seen by the fission product containing fuel,

$\sigma^{2} \mathrm{FP}$ is an averaged "lump" fission product absorption cross section, and

$\tau$ is a characteristic removal processing time for the fission products.

The value of $\alpha_{F P}$ varies as the fission product isotopics, and hence $\sigma^{a} F$, shift with time; however, an equilibrium value is reached in times which are short with respect to blanket module lifetimes. The characteristic fission product processing time $\tau$ is defined as

$$
\frac{1}{\tau}=\sum_{i} \frac{f_{i}}{\tau_{i}}
$$

where

$f_{i}$ is the fraction of the fission product concentration which is element species $i$, and

$\tau_{\mathrm{i}}$ is the processing time for element species $\mathrm{i}$.

\section{B. Contribution of Lono-Lived Fission Product Iransmutation to Reactivity}

The values of $\alpha_{\mathrm{LL}}$ are determined by the relative isotopic feeds and activation chains for each species. These chains are illustrated in the following figure for major long-lived fission products.

Long-lived fission products can be introduced into the ABC/ATW system via internal feed (resulting from fissioning of plutonium and other actinides in the system) and/or through external feed of selected products. Representative isotopic and elemental feeds for such long-lived fission products are determined through ORIGEN2 calculations. The spent fuel concentrations for each LLFP species were 

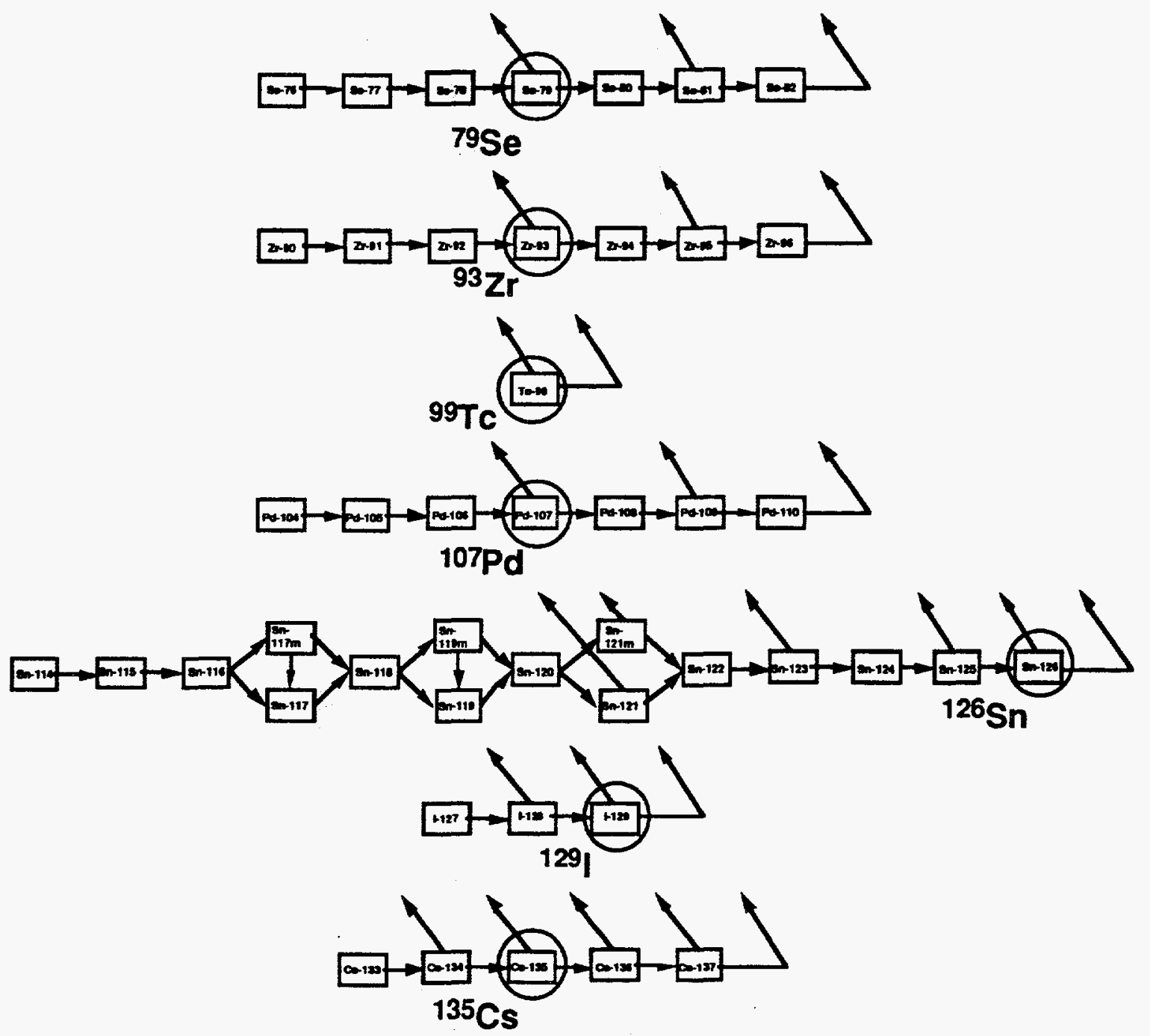

Figure F1: Long-Lived Fission Product Chains

those in PWR/U fuel exposed for 33 GW-d and cooled for 10 years. Isotopic feed is then expressed as moles of spent-fuel LLFP chain species i per mole of spent-fuel actinide fission in a system burning both actinides and LLFPs in equilibrium. The internal production isotopics for each LLFP species were calculated as a function of flux level and characteristic processing time in an equilibrium ATW actinide fuel where over $85 \%$ of the fission occurs in Pu-239. Isotopic feed is then expressed as moles of LLFP chain species i recovered in processing per mole of actinide fission in a system burning actinides at equilibrium. The total calculated chain feed for both elemental and isotopic ( $100 \%$ enriched) feeds are presented in Table F1.

The value of $\alpha^{i} L L$ for internal recycle is strongly dependent on the relative values of the average neutron flux seen by the fission product containing fuel and of the characteristic removal processing time for the LLFP. At long relative residence times, significant transmutation of the LLFP occurs in the fuel before recovery and appears as a contribution to $\alpha F P$ rather than to $\alpha$ LL. The total impact on reactivity for LLFP species $i$ is given by the sum of $\alpha^{i}$ FP and $\alpha^{i} L L$. 
Table F1: Total chain feed for equilibrium LLFP chain calculations.

\begin{tabular}{|c|c|c|c|}
\hline \multicolumn{5}{|c|}{$\begin{array}{c}\text { Isotopic Feed } \\
\text { (moles/mole of fission) } \\
\text { Isotope }\end{array}$} & $\begin{array}{c}\text { Internal } \\
\text { Only }\end{array}$ & $\begin{array}{c}\text { External } \\
\text { Only }\end{array}$ & $\begin{array}{c}\text { Externalt } \\
\text { Internal }\end{array}$ \\
\hline Se-79 & $3.89 \mathrm{E}-04$ & $1.83 \mathrm{E}-03$ & $2.22 \mathrm{E}-03$ \\
\hline Zr-93 & $3.56 \mathrm{E}-02$ & $1.90 \mathrm{E}-01$ & $2.26 \mathrm{E}-01$ \\
\hline Tc-99 & $4.83 \mathrm{E}-02$ & $1.92 \mathrm{E}-01$ & $2.40 \mathrm{E}-01$ \\
\hline Pd-107 & $3.38 \mathrm{E}-02$ & $5.02 \mathrm{E}-02$ & $8.40 \mathrm{E}-02$ \\
\hline Sn-126 & $1.69 \mathrm{E}-03$ & $5.34 \mathrm{E}-03$ & $7.02 \mathrm{E}-03$ \\
\hline I-129 & $9.81 \mathrm{E}-03$ & $3.41 \mathrm{E}-02$ & $4.39 \mathrm{E}-02$ \\
\hline Cs-135 & $1.00 \mathrm{E}-02$ & $5.47 \mathrm{E}-02$ & $6.47 \mathrm{E}-02$ \\
\hline & \multicolumn{4}{|c|}{ Elemental Feed } \\
\hline LLFP & Internal & External & External+ \\
\hline Element & Only & Only & Internal \\
\hline selenium & $4.31 \mathrm{E}-03$ & $2.15 \mathrm{E}-02$ & $2.58 \mathrm{E}-02$ \\
\hline zirconium & $3.32 \mathrm{E}-01$ & $2.11 \mathrm{E}+00$ & $2.45 \mathrm{E}+00$ \\
\hline technetium & $4.83 \mathrm{E}-02$ & $1.92 \mathrm{E}-01$ & $2.40 \mathrm{E}-01$ \\
\hline palladium & $4.96 \mathrm{E}-01$ & $1.01 \mathrm{E}+00$ & $1.50 \mathrm{E}+00$ \\
\hline tin & $7.71 \mathrm{E}-03$ & $5.19 \mathrm{E}-02$ & $5.96 \mathrm{E}-02$ \\
\hline iodine & $1.36 \mathrm{E}-02$ & $4.49 \mathrm{E}-02$ & $5.85 \mathrm{E}-02$ \\
\hline cesium & $1.37 \mathrm{E}-01$ & $5.75 \mathrm{E}-01$ & $7.13 \mathrm{E}-01$ \\
\hline
\end{tabular}




\section{Appendix G}

\section{Neutron Economy Impacts Associated with LLFP Integrated Dose Reduction}

The total integrated dose $d_{i}\left(t_{R}\right)$ per nuclide emplaced in a geologic repository per unit volume of contaminated water released to the accessible environment at reference post-release time th due to species i (rems/nuclide) can be expressed as

$$
d_{i}\left(t_{R}\right)=\frac{D_{i}\left(t_{R}\right)}{l_{i}^{O}}=\frac{c_{i}}{\lambda_{i}} \beta_{i}\left(t_{E}\right) \gamma_{i}\left(t_{w}\right) \delta_{i}\left(t_{R}\right)
$$

from Eq. E.15 of Appendix E. A quantity $w_{i}$ can be defined as the integrated LLFP dose reduction per neutron capture per transmutation of LLFP species i given by

$$
w_{i}=\frac{d_{j}\left(t_{R}\right)}{\chi_{L L}^{i}}
$$

where the parameter $\chi^{i} L L$ is defined as the number of neutron captures required for transmutation of LLFP species $i$. This latter value is not 1.0 because other isotopes of species $i$ as well as other elemental transmutation products (TPS) of species i may be present as additional absorbers. The parameter $\chi L L$ is given by

$$
\chi_{L L}^{i}=g_{L L}^{i}\left(1+g_{T P}^{i}\right)
$$

where

$\mathrm{g}_{\mathrm{LL}}^{\mathrm{i}}$ is the number of total captures in LLFP species $\mathrm{i}$ chain per LLFP nuclide fed to the chain at equilibrium and

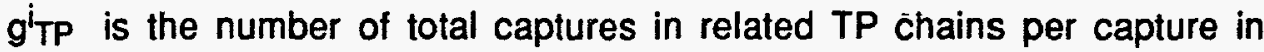
the LLFP species i chain.

This value of $g^{i} L L$ is illustrated in Figures $G_{1}$ and $G 2$ for transmutation of the LLFP Cs-135. Note that for elemental fission-product cesium transmutation (Figure G1), a total of 3.789 Cs-135 nuclides of are "burned" per Cs-135 nuclide "fed" to the system. Also, 10.518 neutron captures in the equilibrium cesium chain are required per Cs-135 nuclide "fed" to the system. For isotopically pure feed (Figure G2), only 1.0007 neutron captures in the equilibrium cesium chain are required per Cs-135 nuclide "fed" to the system.

The parameter $\mathrm{g}^{\mathrm{i}} \mathrm{TP}$ accounts for the absorption in transmutation products (TPS) of species $i$ which are not the same element. This allows separate recovery and recycle processing for the LLFP and TP elements. The TPS can contribute significantly to the total absorption associated with elimination of species $i$; this absorption is strongly dependent on the rate at which the LLFP transmutation loops are processed for TP removal relative to their production rate or neutron flux level. The predominant absorption is in the element of next higher $Z$ (e.g., ruthenium for technetium). The value of giTP for TC-99 transmutation is presented in Figure G3. 


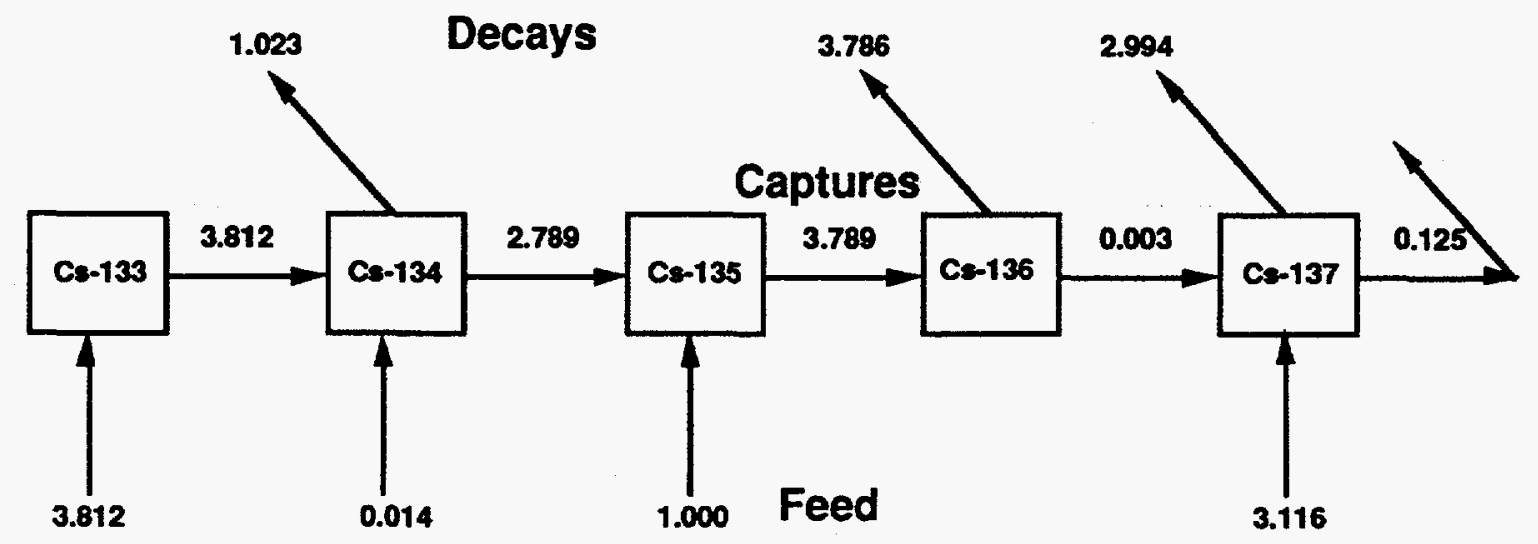

Figure G1: Equilibrium transmutation chain for Cs-135 assuming spent-fuel elemental fission-product cesium as feed to transmutation system.

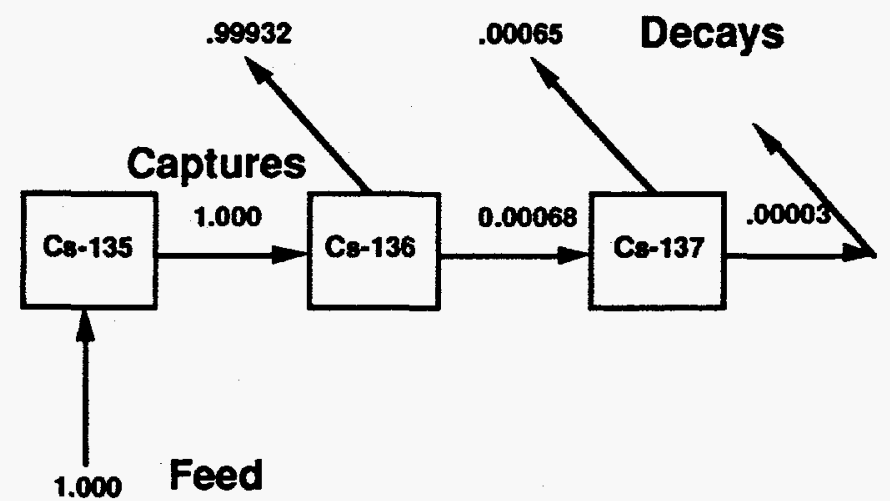

Figure G2: Equilibrium transmutation chain for Cs-135 assuming 100\% isotopically enriched Cs-135 as feed to transmutation system.

Values of $\mathrm{g}^{\mathrm{i} L \mathrm{~L}}$ for spent-fuel fission-product feed are presented in Table E3.

Table G1: The number of neutron captures required for transmutation of LLFP species i for spent fuel (10-year-old, $33 \mathrm{GW}$-d) feed isotopics, a neutron flux level of $4 \times 10^{14}$, and a CANDU thermal spectrum.

\begin{tabular}{|l|c|c|}
\hline & $\begin{array}{c}\text { g'TP }^{\prime} \\
\text { Isotopic } \\
\text { Feed }\end{array}$ & $\begin{array}{c}\text { g'TP }^{\prime} \\
\text { Elemental } \\
\text { Feed }\end{array}$ \\
\hline Se-79 & 1.999 & 11.740 \\
\hline $\mathrm{Zr}-93$ & 2.002 & 11.110 \\
\hline Tc-99 & 1.000 & 1.000 \\
\hline Pd-107 & 2.000 & 20.060 \\
\hline Sn-126 & 1.000 & 9.696 \\
\hline I-129 & 1.000 & 1.316 \\
\hline Cs-135 & 1.001 & 10.520 \\
\hline
\end{tabular}




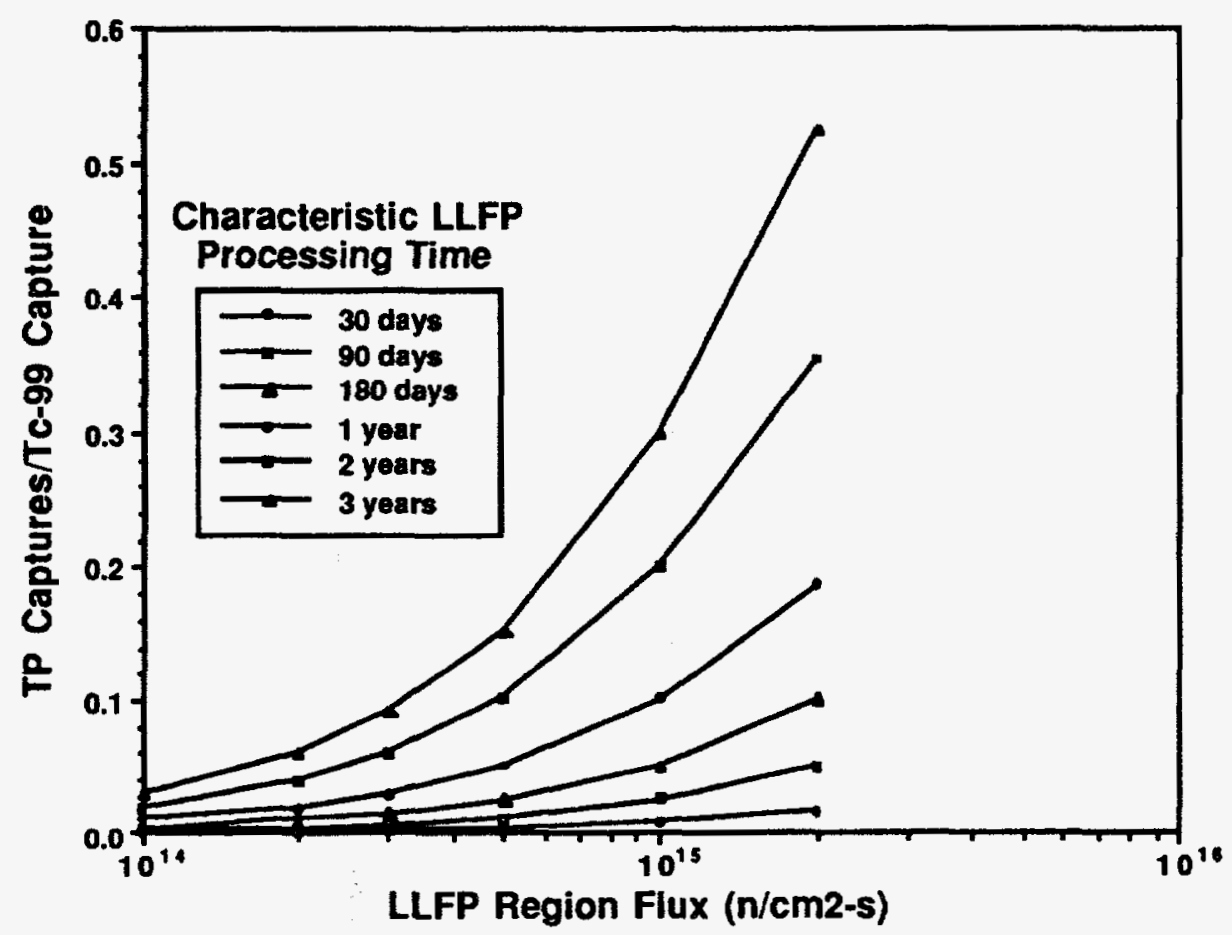

Figure G3: Captures (per Tc-99 capture) in ruthenium and other transmutation products as a function of processing time and flux level.

Values of $\mathrm{g}^{\mathrm{T}} \mathrm{TP}$ for spent-fuel fission-product feed are presented in Table G2.

Table G2: The number of neutron captures in transmutation products per absorption in the LLFP equilibrium chain at a neutron flux level of $4 \times 10^{14}$, in a CANDU thermal spectrum, and with a LLFP-TP separation processing characteristic time of $180 \mathrm{~d}$.

\begin{tabular}{|c|c|c|}
\hline & $\begin{array}{c}9^{\prime} \mathrm{LL} \\
\text { Isotopic } \\
\text { Feed }\end{array}$ & $\begin{array}{c}\text { g'LL }^{\prime} \mathrm{Elemental} \\
\text { Feed }\end{array}$ \\
\hline $\mathrm{Se}-79$ & 0.128 & 0.007 \\
\hline $\mathrm{Zr}-93$ & 0.014 & 0.013 \\
\hline $\mathrm{TC}-99$ & 0.003 & 0.003 \\
\hline $\mathrm{Pd}-107$ & 1.009 & 0.027 \\
\hline $\mathrm{Sn}-126$ & 0.006 & 0.002 \\
\hline $\mathrm{I}-129$ & 0.004 & 0.004 \\
\hline $\mathrm{Cs}-135$ & 0.001 & 0.001 \\
\hline
\end{tabular}

The quantity $w_{i}$ defined in Eq. G.2 is the integrated LLFP dose reduction per neutron capture per transmutation of LLFP species i only. In order to compare LLFP transmutation strategies, a parameter $W_{i}$ is defined which accounts for the relative 
LLFP production rates from fission or concentrations in spent fuel. $W_{i}$ is the integrated LLFP dose reduction (due to transmutation of LLFP species i) per neutron capture per LLFP and is given by

$$
W_{i}=\frac{w_{i}}{y_{L L}^{i}}
$$

where

$y_{L L}$ is the species i fraction (isotopic or elemental) of the total LLFPs (isotopic or elemental).

$W_{i}$ can be expressed in terms of the integrated dose reduction per nuclide $d_{i}\left(t_{R}\right)$ and the various chain efficiency parameters $g^{i} L L, g^{i} T P$, and $y^{i} L L$ as

$$
W_{i}=\frac{d_{i}\left(t_{R}\right)}{g_{L L}^{i}\left(1+g_{T P}^{i}\right) y_{L L}^{i}}
$$

Whether the LLFPs are in isotopic or elemental form is determined by the LLFP transmutation strategy adopted, which in turn is based on evaluation of dose reduction effectiveness versus cost. The values of $y^{i} \mathrm{LL}$ are presented in Tables $\mathrm{G} 3$ for all isotopic strategy and an elemental strategy, respectively.

In order to assess the relative dose reduction effectiveness per neutron utilized, the ratio of $W_{i}$ to that for a reference LLFP species $j(e .9 .$, Tc-99) is defined. This ratio $E_{i T c}$ is a measure of the neutron dose-reduction effectiveness relative to that for TC-99. The LLFP is selected both because of its dominance in repository release but also because of simple one-isotope, large cross-section impact on neutron economy. The ratio is given by

$$
\begin{aligned}
E_{i j} & =\frac{d_{i}\left(t_{R}\right) g_{L L}^{i}\left(1+g_{T P}^{j}\right) y_{L L}^{j}}{d_{j}\left(t_{R}\right) g_{L L}^{i}\left(1+g_{T P}^{i}\right) y_{L L}^{i}} \\
& =\frac{c_{i} \beta_{i}\left(t_{E}\right) \gamma_{i}\left(t_{w}\right) \delta_{i}\left(t_{R}\right) \lambda_{j} g_{L L}^{j_{L}}\left(1+g_{T P}^{j}\right) y_{L L}^{j}}{c_{j} \beta_{j}\left(t_{E}\right) \gamma_{j}\left(t_{W}\right) \delta_{j}\left(t_{R}\right) \lambda_{i} g_{L L}^{i}\left(1+g_{T P}^{i}\right) y_{L L}^{i}}
\end{aligned}
$$

The parameter $E_{i T c}$ is a measure of relative LLFP transmutation effectiveness with respect to accelerator-produced neutron utilization. It can be used to evaluate LLFP transmutation strategies as well as to identify critical cost-performance trades.

\section{A Assessment of The Neutron-Induced Dose-Reduction Effectiveness Of $L L F P$}

\section{Iransmutation Strategies}

The measure of neutron-induced dose reduction effectiveness $E_{i T c}$ defined above requires the additional definition of an LLFP transmutation strategy (i.e., the number and isotopics of LLFPs to be transmuted as well as whether externally and/or internally generated LLFPs are to be transmuted. To illustrate the method, a strategy is defined which is based on an ADEP system which burns all of its internally generated LLFPs. 
Table G3: Values of y'LL for external feed and internal recycle.

\begin{tabular}{|c|c|c|c|}
\hline \multicolumn{5}{|c|}{$\begin{array}{c}\text { Isotopic Feed Fraction } \\
\text { (moles/mole of total feed) }\end{array}$} \\
\hline $\begin{array}{c}\text { LLFP } \\
\text { Isotope }\end{array}$ & $\begin{array}{c}\text { Internal } \\
\text { Only }\end{array}$ & $\begin{array}{c}\text { External } \\
\text { Only }\end{array}$ & $\begin{array}{c}\text { External+ } \\
\text { Internal }\end{array}$ \\
\hline Se-79 & 0.003 & 0.003 & 0.003 \\
\hline $\mathrm{Zr}-93$ & 0.360 & 0.255 & 0.338 \\
\hline Tc-99 & 0.363 & 0.346 & 0.359 \\
\hline Pd-107 & 0.095 & 0.242 & 0.126 \\
\hline Sn-126 & 0.010 & 0.012 & 0.011 \\
\hline I-129 & 0.065 & 0.070 & 0.066 \\
\hline Cs-135 & 0.104 & 0.072 & 0.097 \\
\hline \multicolumn{5}{|c|}{ Elemental Feed Fraction } \\
\hline LLFP & Internale of total feed) & External & External+ \\
\hline Element & Only & Only & Internal \\
\hline selenium & 0.009 & 0.006 & 0.008 \\
\hline zirconium & 0.480 & 0.333 & 0.448 \\
\hline technetium & 0.096 & 0.088 & 0.094 \\
\hline palladium & 0.158 & 0.309 & 0.191 \\
\hline tin & 0.017 & 0.008 & 0.015 \\
\hline iodine & 0.022 & 0.025 & 0.023 \\
\hline cesium & 0.218 & 0.231 & 0.221 \\
\hline
\end{tabular}

The isotopic composition of the LLFPs recycled is based on crude assumptions about cost impacts of enrichment. The LLFPS TC-99 and 1-129 are recycled in their elemental form because technetium has a single isotope and iodine has only two but is dominated by $1-129$. The LLFPs $\mathrm{Sn}-126$ and Cs-135 are recycled as $100 \%$ enriched because these nuclides are on the end of their respective chains and require only a single enrichment following recovery from the thorium/uranium fuel. The LLFPs Se-79, Zr-93, and Pd-107 are recycled in elemental form because they are in the middle of their respective chains and would require continuous enrichment as part of the processing to recover the transmutation products. The values of $g^{i} L L$, g'TP, and $y^{\prime} L L$ are presented in Table G4 for this strategy. These values assume a flux level of $4 \times 10^{14}$ in both the fuel and LLFP transmutation regions, a characteristic fuel processing time of 30 days for recovery of the LLFPs, and a characteristic processing time of 180 days for removal of the TPS for the LLFP loops. 
Table G4: Values of gíL, g'TP, and $y^{i} L L$ for an example ADEP LLFP transmutation strategy.

\begin{tabular}{|c|c|c|c|}
\hline $\begin{array}{c}\text { LLFP } \\
\text { Form }\end{array}$ & $\begin{array}{c}g^{\prime} L L \\
\text { (moles/mole) }\end{array}$ & $\begin{array}{c}g^{\prime} T P \\
\text { (moles/mole) }\end{array}$ & $\begin{array}{c}y^{i} L L \\
\text { (moles/mole) }\end{array}$ \\
\hline selenium & 10.960 & 0.033 & 0.008 \\
\hline zirconium & 8.660 & 0.086 & 0.453 \\
\hline technetium & 1.000 & 0.020 & 0.133 \\
\hline palladium & 9.524 & 0.125 & 0.352 \\
\hline Sn-126 & 1.000 & 0.037 & 0.004 \\
\hline iodine & 1.310 & 0.025 & 0.037 \\
\hline Cs-135 & 1.001 & 0.002 & 0.012 \\
\hline
\end{tabular}




\section{Appendix $\mathrm{H}$}

\section{Impact Of LLFP Transmutation on Neutron Economy}

The impact of LLFP transmutation on neutron economy may also be assessed in terms of dose reduction. Using the values of $\alpha_{L L}$ for the LLFP transmutation strategy described above (see Figure 8), a value of the cumulative dose reduction (relative to Tc-99) as a function of the $\Delta \mathrm{k}_{\text {eff }}$ can be calculated. A reference value of $k_{\text {eff }}$ for burning Tc-99 (without internal recycle) and actinides present in spent fuel as well as the representative values of $v, p_{N L}, \alpha_{F}, \alpha_{S} / T$, and $\alpha_{F P}$ (based on equilibrium burning of spent-fuel actinides in a well-moderated target-blanket neutron flux spectrum) are presented in Table $\mathrm{H} 1$.

Table H1: Values of $\alpha_{L L}$ for the LLFP transmutation strategy presented in G.1 above.

\begin{tabular}{|l|c|}
\hline $\begin{array}{c}\text { LLFP } \\
\text { isotope or } \\
\text { element }\end{array}$ & $\begin{array}{c}\text { Equilibrium } \\
\alpha \mathrm{\alpha LL} \\
\text { (external } \\
\text { feed) }\end{array}$ \\
\hline selenium & 0.0258 \\
\hline zirconium & 2.4450 \\
\hline technetium & 0.2400 \\
\hline palladium & 1.5020 \\
\hline Sn-126 & 0.0070 \\
\hline iodine & 0.0585 \\
\hline $\mathrm{Cs}-135$ & 0.0647 \\
\hline
\end{tabular}

Table H2: Reference neutron economy parameters for the LLFP transmutation strategy presented in G.1 above.

\begin{tabular}{|c|c|}
\hline $\begin{array}{c}\text { Neutron } \\
\text { economy } \\
\text { parameter }\end{array}$ & $\begin{array}{c}\text { Equilibrium } \\
\text { value }\end{array}$ \\
\hline$v$ & 3.0451 \\
\hline $\mathrm{PNL}$ & 0.9842 \\
\hline$\alpha \mathrm{S} / \mathrm{T}$ & 0.1752 \\
\hline$\alpha \mathrm{F}$ & 1.6033 \\
\hline$\alpha \mathrm{FP}$ & 0.1521 \\
\hline$\alpha \mathrm{Tc}$ & 0.2400 \\
\hline $\mathrm{K}_{\text {eff }}$ & 0.9453 \\
\hline
\end{tabular}

The cumulative relative dose reduction for the LLFPs is calculated based on an order determined by decreasing incremental values (i.e., the first LLFP to be transmuted beyond Tc-99 is the one with the largest relative dose reduction). Since operation at large $\Delta \mathbf{k}_{\text {eff }}\left(\boldsymbol{k}_{\text {eff }}<0.9\right)$ translates into large accelerator requirements and hence cost, there is a strong incentive to identify other management strategies for the LLFPs with minimal dose impacts. 